\title{
DEVELOPMENTS IN THE TREATMENT OF SYPHILIS WITH ARTIFICIAL FEVER THERAPY COMBINED WITH CHEMO- THERAPY DURING THE PAST DECADE
}

"." Fever is a mighty engine which Nature brings into the world for the conquest of her enemies." -SYDENHAM (1624-I689).

By WÁLTER M. SIMPSON, M.D., F.A.C.P.,* H. WORLEY KENDELL, M.D, and DONALD ROSE, M.D.

Director, Associate Director and Research Associate, Respectively, of the Kettering Institute for Medical Research, Miami Valley Hospital, Dayton, Ohio, U.S.A.

\section{INTRODUCTION}

ON May 22, I936, it was the privilege of one of us (Simpson) to deliver an address before the Medical Society for the Study of Venereal Diseases on "Artificial Fever Therapy of Syphilis and Gonococcic Infections." The published address appeared in The British Journal of Venereal Diseases for July, I936. The report was based upon observations made during a five-year study of the application of artificial fever therapy to various disease processes. At the conclusion of the lecture an invitation was extended to members of the Society to visit the Kettering Institute for Medical Research for the purpose of observing the work at first hand. The invitation was accepted by Mr. Ambrose J. King, F.R.C.S., a VicePresident of the Medical Society for the Study of Venereal Diseases, after conferences with Colonel L. W. Harrison. Colonel E. T. Burke, Dr. Arthur H. Harkness and other colleagues. Mr. King came to Dayton for a period of several weeks of observation and instruction during the spring of I937. A report of Mr. King's experiences, entitled " Fever Therapy at Dayton, Ohio," appeared in

* Honorary Member of the Medical Society for the Study of Venereal Diseases ; Special Consultant, Division of Venereal Diseases, U.S. Public Health Service; Commander, Me Jical Corps, U.S. Naval Reserve. 


\section{BRITISH JOURNAL OF VENEREAL DISEASES}

the British Journal of Venereal Diseases for October, 1937. Mr. King also observed the work in artificial fever therapy at the University of Rochester, at the University of Pennsylvania and at several clinics in New York City. $\mathrm{He}$ also attended the International Conference on Fever Therapy in New York City in March, 1937. Shortly thereafter, work in this field was launched at the London Hospital (Whitechapel Clinic), utilising the Kettering hypertherm, under the directorship of Mr. King. The work was progressing with eminently satisfactory results when it was interrupted abruptly by the exigencies of war.

The present report has been prepared in response to a request received from Colonel Harrison for a critical review of developments in the use of artificial fever therapy in the management of syphilis, including a further report of our work in this field during the past ten years.

\section{NEUROSYPHILIS}

Fortified by the experiences of a decade it can now be stated that artificial fever therapy* of neurosyphilis is at least as effective as malaria therapy. The past five years have witnessed a notable decline in the hyperenthusiastic and sometimes extravagant claims made by certain advocates of one or the other method. Out of the controversy has emerged a more rational clarification of the relative merits of the two procedures. Several recent authoritative communications have contributed to this wholesome situation.

Appraisal of Malaria Therapy and Artificial Fever THERAPY BY WAGNER-JAUREGG

The brilliant analysis of "The Present Management of Progressive Paralysis," by Julius Wagner-Jauregg, published in I939 (I), a short time before his death, is a masterpiece of unprejudiced objectivity. After examining critically the results attained with malaria therapy and with artificial fever therapy, Wagner-Jauregg, the father of malaria therapy, made these significant statements :

"The method of treatment by elevation of body tem-

"The term "artificial fever therapy" denotes the production of fever by physical means. 
perature to the height of fever by physical means has been used in a large number of diseases and has been shown to be very valuable. In so far as used in progressive paralysis the methods concur with malaria therapy . . . Results show that after treatment of progressive paralysis (with physically induced fever) there were remissions similar to those which occur in patients treated with malaria. Also many have found that treatment of paralytics with physically induced fever gave a number of full remissions as great or greater than with malaria. The number of improvements was equally good.

" Furthermore, it is a well-known advantage of artificial fever that one can regulate the height of the temperature reached, the length of the fever period and the length of fever-free rest periods according to the condition of the patient. Moreover, during the course of treatment continuous hospitalization is not necessary. The last special consideration occurs when a case that is not one of clear-cut progressive paralysis, but is one with a latent positive spinal fluid, requiring prophylactic treatment. Also those sick people who can still continue their ordered business life require several weeks of interference with their work if malarial treatment is used. Finally, if following artificial fever and chemotherapy, the goal of treatment is not reached, namely, the production of negative spinal fluid, then one still has time to utilize malarial treatments ...

"A few weeks after the ending of the fever treatment it is the rule that one can determine if a full remission is to be expected and those having an unfavourable prognosis can be called back. It is fortunate that the possibility exists to change the type of fever treatment ; accordingly, a malarial treatment may be substituted for artificial fever or vice versa.

"Too little use is made of divided malarial treatments. In this type, after three or at the most four attacks of fever the malaria is controlled by quinine. Then after an interval during which specific treatment is carried out, a new malarial inoculation is made. The patient in the meantime has recovered and can better tolerate longer treatments than during the first half of the course. Such divided methods can be carried out more easily with artificial fever.

"Admitting that experience has determined from a 
great amount of material that malaria and artificial fever combined with intensive treatment with pentavalent arsenicals gives on the average the same number, degree and length of remissions there must also be non-medical considerations in the choice of the method. One must observe the question from an economic standpoint. So far as the fever-producing agents are concerned the malarial treatment has an unquestioned advantage. The little cubic centimeter of blood which is necessary for the treatment of paralytics costs nothing, and even supposing that the material for injection comes from another place there is no important cost. Furthermore, sick persons can be treated together in a room under supervision of a trained nurse or orderly. The artificial fever apparatus is costly. During the course of a treatment the uninterrupted presence of a person trained in the complex technic of the apparatus is necessary. Also only as many cases may be treated simultaneously as there is available equipment.

" Truly one advantage of the artificial fever treatment must be brought forward, namely, that it is innocuous compared to the danger of malarial treatment (as regards fatalities)."

RePort of CoMmitTeE ON NON-SPECIfic Therapy OF Syphilis, U.S. Public Health Service

In August, I936, about three years before WagnerJauregg's classic report appeared, Dr. Thomas Parran, Surgeon-General of the U.S. Public Health Service, appointed a sub-committee of the Co-operative Clinical Group to study and to evaluate the various forms of nonspecific therapy used in the treatment of neurosyphilis. This committee was composed of Dr. Paul A. O'Leary (Chairman), Mayo Clinic, Rochester, Minnesota; Dr. Walter L. Bruetsch, Central State Hospital, Indianapolis, Indiana ; Dr. Franklin G. Ebaugh, University of Colorado Psychopathic Hospital, Denver, Colorado; Dr. Harry C. Solomon, Boston Psychopathic Hospital, Boston, Massachusetts ; Dr. Stafford L. Warren, University of Rochester, Rochester, New York; and one of us (Simpson). All had had extensive experience with either malaria therapy or with artificial fever therapy or with both. Dr. R. A. Vonderlehr, Assistant Surgeon General, 


\section{FEVER THERAPY}

Division of Venereal Diseases, U.S. Public Health Service, was also a member of the committee and was assisted by Miss Lida J. Usilton, I. V. Sollins, A. P. Iskrant and other members of the Statistical Division of the U.S. Public Health Service.

In addition to submitting to the U.S. Public Health Service for statistical analysis clinical records from all of the institutions represented by the members of the committee, the following clinic directors offered for analysis the records from their institutions: Dr. A. E. Bennett, University of Nebraska, Omaha ; Dr. Harold N. Cole; Western Reserve University, Cleveland; Dr. J. R. Blalock and Dr. Leland E. Hinsie, New York State Psychiatric Institute, New York City; Dr. Frank R. Menagh, Henry Ford Hospital, Detroit ; and Captain Ernest H. Parsons, M.C., U.S. Army, Fitzsimons General Hospital, Denver.

It required nearly four years to collect the data and to subject it to rigid analysis by disinterested professional statisticians. The report of the Committee, on "Malaria and Artificial Fever in the Treatment of Paresis," appeared in August, I940 (2). The study was designed to compare the therapeutic results obtained by the use of artificial fever produced by physical methods with those obtained by the use of inoculated malaria in the treatment of paresis (dementia paralytica). The results were evaluated in terms of both clinical and serologic responses observed after the independent use of either method of fever therapy, with or without the associated employment of chemotherapy.

Only unequivocally paretic patients who had been observed for more than two years following the commencement of fever therapy were considered. The records of $I, 420$ such patients were pooled for statistical study. Of these, I, Ioo patients were treated with malaria and 320 with artificial fever.

All were classified by the degree of syphilitic meningoencephalitic involvement when fever therapy was begun. Patients with " mild paresis" were relatively free from signs of deterioration and their mental symptoms were usually transitory. Those classified as having "intermediate paresis" exhibited symptoms of manic excitement, depression or other psychiatric syndromes, in addition to evidence of moderate deterioration. The 
third classification, that of " severe paresis," included those who gave evidence of advanced deterioration.

The clinical results of therapy were defined as: (a) "remission," in which there was sufficient clinical recovery to permit the patient to return to his former socio-economic status; (b) " improved," which denoted complete or partial disappearance of clinical manifestations without corresponding improvement in the capacity to return to the former socio-economic status ; (c) " unimproved," in which there was no detectable clinical evidence of change in the course of the disease ; (d) "progressed," which indicated that the clinical status was less satisfactory after treatment than before ; and $(e)$ " death," which included deaths during therapy, or deaths regardless of cause occurring within three months subsequent to therapy.

\section{CHART I}

CMCMOTHCRAPY
TRYPARSAMIOE AND
MEAVY METALS.
1926-1931

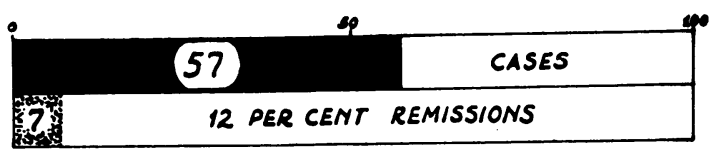

MALARIA ROLLOWED

OY CHEMOTHERAPY.

$1931-1936$
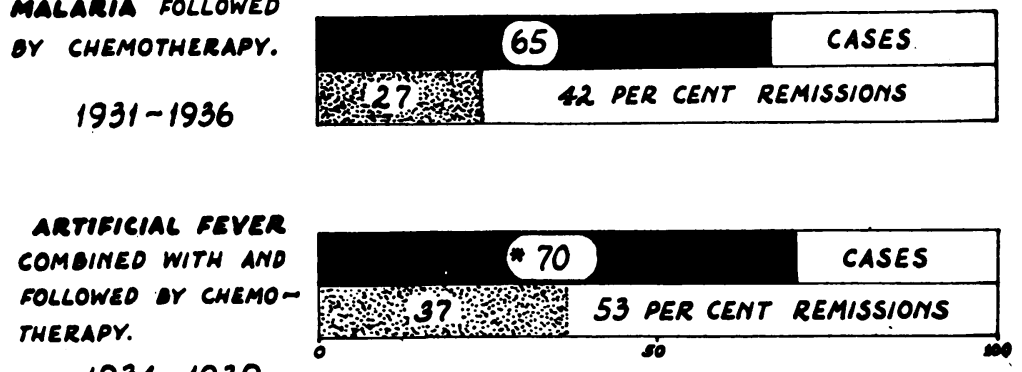

$1934-1939$

- The 70 cases include 30 from the University of Nebraska Fever Therapy Research Department having 56 per cent remissions, and 40 committed paretics at Hastings State Hospital, including 12 chronic malarial failures, with 47.5 per cent remissions.

The yearly clinical remission rates per roo patients treated were cumulated by the method of therapy and by the degree of paretic involvement when fever therapy 


\section{FEVER THERAPY}

was begun. Thus, the total successful results of therapy were determined at the conclusion of any given year within the entire period of treatment and post-therapy observation. The increase in the percentage of successful outcomes of therapy within a given year could thus be obtained by subtraction (Table I.).

Table I.-Average Yearly Clinical Remission Rates (Cumulated)

(Committee on Non-Specific Therapy of Syphilis, U.S. Public Health Service)

THREE-Year TrEatMent-OBSERVATION

\begin{tabular}{|c|c|c|c|c|c|c|c|c|}
\hline \multirow{3}{*}{$\begin{array}{l}\text { End of each Year } \\
\text { of Treatment- } \\
\text { Observation. }\end{array}$} & \multicolumn{8}{|c|}{ Rate of Remission per roo Paretics under Treatment-Observation. } \\
\hline & \multicolumn{2}{|c|}{ Mild. } & \multicolumn{2}{|c|}{ Intermediate. } & \multicolumn{2}{|c|}{ Severe. } & \multicolumn{2}{|c|}{ Total. } \\
\hline & Malaria. & $\begin{array}{c}\text { Artificial } \\
\text { Fever. }\end{array}$ & Malaria. & $\begin{array}{c}\text { Artificial } \\
\text { Fever. }\end{array}$ & Malaria. & $\begin{array}{c}\text { Artificial } \\
\text { Fever. }\end{array}$ & Malaria. & $\begin{array}{l}\text { Artificial } \\
\text { Fever. }\end{array}$ \\
\hline I & $36 \cdot 4$ & $37 \cdot 7$ & 13.7 & $I 6 \cdot 2$ & $0 \cdot 0$ & $3 \cdot 9$ & I3.8 & $I 8 \cdot 0$ \\
\hline 2 & $45 \cdot \mathrm{I}$ & $48 \cdot 4$ & $20 \cdot 2$ & $2 \mathrm{I} \cdot \mathrm{O}$ & 0.5 & $9 \cdot 0$ & I8.9 & $24 \cdot 7$ \\
\hline 3 & $51 \cdot 7$ & $50 \cdot 2$ & $24 \cdot 2$ & $23 \cdot 6$ & 0.9 & II $\cdot 3$ & $22 \cdot 4$ & $27 \cdot 2$ \\
\hline
\end{tabular}

Four-Year Treatment-ObSERVATION

\begin{tabular}{|c|c|c|c|c|c|c|c|c|}
\hline I & $36 \cdot 4$ & $35 \cdot 2$ & 13.3 & I6. 8 & $0 \cdot 0$ & $2 \cdot 9$ & $13 \cdot 4$ & 16.9 \\
\hline 2 & 44.7 & $45 \cdot 9$ & $19 \cdot 6$ & I9.2 & 0.5 & $8 \cdot 6$ & $I 8 \cdot 4$ & $22 \cdot \overline{6}$ \\
\hline 3 & $5 \mathrm{I} \cdot 9$ & $47 \cdot 3$ & 23.5 & $22 \cdot 0$ & $I \cdot O$ & II $\cdot 3$ & $2 \mathrm{I} \cdot 9$ & $25 \cdot I$ \\
\hline 4 & $52 \cdot 3$ & $52 \cdot 8$ & $25 \cdot I$ & $30 \cdot 9$ & $I \cdot O$ & $\mathrm{II} \cdot 3$ & $22 \cdot 8$ & $30 \cdot 3$ \\
\hline
\end{tabular}

As regards the patients with mild or intermediate paresis there were no statistically significant differences between the rates of remission obtained with malaria therapy and those obtained with artificial fever therapy. In other words, equally good clinical results were obtained following either method of fever therapy in patients with mild or intermediate paresis. Sharp and statistically reliable differences were noted, however, between the results of the two methods of therapy among patients suffering from severe paresis at the beginning of fever therapy; here there was distinct superiority of remission rates following artificial fever therapy, as noted in Table I.

The clinical responses were best when fever therapy was instituted early in the course of the disease. Thus, 


\section{BRITISH JOURNAL OF VENEREAL DISEASES}

at the end of three or four years of treatment-observation, more than one-half of the patients with mild paresis treated with either method of therapy had clinical remissions. Similarly, with either method of fever therapy, the rates for clinical recovery were reduced to approximately one in four patients with intermediate paresis. While the proportion of remissions was distinctly less in patients with severe paresis, II per cent. of patients with severe paresis obtained clinical remission after artificial therapy, while only I per cent. had clinical remission following malaria therapy.

For purposes of this study, treatment deaths were defined as deaths occurring not only during the course of fever therapy but also included all who died regardless of cause during the succeeding three months. Utilizing such criteria, the total crude death rate was higher with malaria (I3 per cent.) than with artificial fever (8 per cent.). The frequency of death was greatest among the patients with severe paresis (25.8 per cent. of malariatreated cases and 17.9 per cent. of those treated with artificial fever). By contrast, among patients with mild paresis there were no deaths during the course of artificial fever therapy and four deaths during malaria therapy; $2 \cdot 3$ per cent. of the patients with mild paresis treated by either method died within three months. Among those with intermediate paresis, 9.4 per cent. of the malariatreated patients and 6.5 per cent. of those treated with artificial fever died during treatment or within three months following treatment. Thus, while these individual differences are not statistically significant, they all point in the same direction in indicating that the percentage of deaths under malaria therapy was higher than with artificial fever therapy within each degree of paretic involvement.

An analysis of the relative speed with which remissions were attained revealed that approximately 90 per cent. of the successful results occurred by the end of the third year by either method. In mild paresis remissions were obtained from one to two years earlier than in intermediate or severe paresis.

If clinical improvement was delayed beyond the second year following fever therapy by either method remission did not occur. Thus, the more prompt the clinical response, the better was the prospect for eventual 


\section{FEVER THERAPY}

remission. Once clinical remission was obtained, the chances of its being maintained were 95 out of roo. There was no statistically valid difference in the relapse rates following either method of fever therapy.

In determining the relation of clinical to serologic results, it was found that clinical success was not accompanied by complete serologic reversal (of blood and of spinal fluid) in more than one-half of the cases. Thus, emphasis is again given to the fact that successful clinical outcome is not necessarily dependent upon serologic response.

Regardless of the method of therapy, the percentages of serologic reversal rates of both blood and spinal fluid increased as the duration of the treatment-observation period grew longer. Positive blood reactions reversed more rapidly though not in greater proportion than positive spinal fluid reactions. The percentage of blood reversals was greater in the malaria-treated group, but reversal occurred more rapidly in those treated with artificial fever.

The necessity for employing auxiliary chemotherapy with either method of fever therapy was indicated by both the significantly higher proportion of spinal fluid reversals and by the maintenance of such reversals in patients receiving concomitant or subsequent chemotherapy or both. In patients treated with fever plus chemotherapy the annual rates of reversal of spinal fluid reactions from positive to negative as well as the rates of blood reversal were higher with malaria than with artificial fever, but this difference was assumed to be due to the greater amount of chemotherapy ( 17 per cent. more) administered to the malaria-treated patients. Without the use of auxiliary chemotherapy there were no differences between the spinal fluid and blood reversal rates of patients treated with malaria and those treated with artificial fever. The reversal rates of blood and spinal fluid were approximately twice as great with as without the use of auxiliary chemotherapy. Among patients not receiving auxiliary chemotherapy 42 per cent. of all spinal fluid reversals subsequently relapsed, as contrasted with 24 per cent. spinal fluid relapses among patients treated with auxiliary chemotherapy.

In three-fourths of the cases in which both clinical and serologic recovery were reported, clinical remission either preceded serologic reversal or occurred during the same 


\section{BRITISH JOURNAL OF VENEREAL DISEASES}

year. When clinical remission preceded serologic reversal, the average difference in time was between two and three years.

A correlation of the clinical outcome with the duration and the intensity of fever, measured by rectal temperature levels, left no doubt that there was a definite correlation between the height and duration of fever and the clinical results. The highest percentage of clinical remissions was obtained in the two groups of patients who experienced either an average of 69 hours of fever above ror F. $\left(38.3\right.$ C.), ${ }^{*}$ of which 70 per cent. was at a level above $105 \mathrm{~F}$. $(40 \cdot 6 \mathrm{C}$.) with a maximum temperature of $106 \cdot 9 \mathrm{~F}$. $(4 \mathrm{I} \cdot 6 \mathrm{C}$.) ; or in those who received an average of 44 hours of fever above IOI F. $(38.3 \mathrm{C}$.) of which total time 57 per cent. were above I06 F. ( $4 \mathrm{I} \cdot \mathrm{I} \mathrm{C}$.) with a maximum temperature of $107 \mathrm{~F}$. $(4 \mathrm{I} \cdot 7 \mathrm{C}$.). On the other hand, the clinical results were distinctly inferior, to the point of being practically nil, in those patients who received an average total of $30 \frac{1}{2}$ hours above IOI $\mathrm{F}$. $(38 \cdot 3 \mathrm{C}$.), with an average of 12.8 sessions of $2 \frac{1}{2}$ hours comprising the total course, with a maximum temperature of 104.9 F. $(40.5 \mathrm{C}$.), and with an average of 26 per cent. of the total fever time at a level between 104 and 104.9 F. (40 to $40.5 \mathrm{C}$.). A careful analysis of the data revealed that no clinical advantages were gained by submitting patients to rectal temperatures above I06.5 F. (4I.4 C.)." The Committee was unanimous in its belief that temperatures between I06.5 and I06.7 F. (4I.4 and $4 \mathrm{I} \cdot 5 \mathrm{C}$.) are apparently the highest rectal temperature levels which can be used with safety in clinical practice, and then only when surrounded by adequate safeguards. Experience has taught that the administration of fever therapy at levels above $106 \cdot 7 \mathrm{~F}$. (4I.5 C.) introduces unnecessary hazards.

REPORT BY EWALT AND EBAUgh, UNIVERSITY OF Colorado, Denver, of Treatment of Alternate Patients with Artificial Fever or Malaria

In his classic appraisal of the relative advantages of artificial fever and malaria therapy, Professor WagnerJauregg (I) directed particular attention to a preliminary report (3) published by Barnacle, Ebaugh and Ewalt of the

* Throughout this report all statements regarding body temperature refer to rectal temperature levels, usually obtained by constantly indicating or recording electrical thermometers. 


\section{FEVER THERAPY}

University of Colorado Psychopathic Hospital in I936, of a comparative study of artificial fever therapy combined with and followed by tryparsamide, and of malaria therapy followed by tryparsamide. Wagner-Jauregg referred to the procedure adopted by Barnacle, Ebaugh and Ewalt as "an excellent plan" for " an equalized investigation of fever therapy by the Kettering hypertherm and by inoculation with malaria."

The Denver investigators, who had had long experience with malaria therapy, decided to employ the " alternate case " method of determining the comparative usefulness of artificial fever therapy and of malaria therapy. Strict alternation was practised in assigning successive patients to one or the other therapeutic program. The same criteria as those adopted by the Committee on NonSpecific Therapy of the U.S. Public Health Service (of which Professor Ebaugh was a member) were used in classifying paretic patients as " mild," "intermediate" or " severe." Thus, the advantages were had of unity of material, time, place and observers.

In the preliminary report (I936) of the therapeutic results accruing from this controlled study of 60 patients during a one year period, it was stated that in the artificial fever-chemotherapy group (30 patients) there was remission in 12 (40 per cent.), as compared with remission in $7(23.3$ per cent.) of the 30 malaria-chemotherapy patients. Nine (30 per cent.) of the patients treated with artificial fever-chemotherapy were improved, while I2 (40 per cent.) of the malaria-chemotherapy patients responded likewise. Thus, of those treated with artificial fever, 2I (70 per cent.) were benefited, as compared with a similarly favourable outcome in I9 (63.3 per cent.) of the malaria-treated patients. No patients died during the course of artificial fever, but one patient died of cerebral hæmorrhage two weeks after the apparently successful conclusion of the course of fever treatments. One patient died during malaria therapy and 3 malaria-treated patients died during the year following treatment.

Here again it was found that the highest proportion of remissions occurred among patients with " mild" paresis. Improvement in spinal fluid serology was comparable in both groups and there was no parallelism between clinical and serologic improvement.

v.D. 
In a current report (4), Ewalt and Ebaugh provide additional information regarding the progress of the original groups of patients and submit data on a five-year comparative study of artificial fever therapy and malaria therapy, based upon the assignment of 232 patients with dementia paralytica either to artificial fever therapy or to therapeutic malaria. The authors were encouraged to continue the comparative study of alternate paretic patients because of the favourable results obtained with artificial fever therapy in the original series, and to determine if possible why " for reasons not entirely clear to the authors, certain clinics treating neurosyphilis have been skeptical of the therapeutic value of artificial fever in this neuropsychiatric disorder."

As the work at the Colorado Psychopathic Hospital progressed it became apparent that certain paretic patients who were not considered to be candidates for malaria therapy because of such concomitant disorders as cerebral arteriosclerosis, chronic nephritis or diabetes, could tolerate artificial fever therapy if due caution was exercised. Hence, the only deviation from the " alternate patient " plan in the more recent study was to include 37 such patients in the group treated with artificial fever and auxiliary chemotherapy. Thus, the totals are brought to I34 patients treated with artificial fever therapy and to 98 patients treated with malaria.

The comparable character of the two groups as regards the type of fever therapy administered to patients in the different clinical categories is shown by the fact that 44 (or 32 per cent.) of the patients treated with artificial fever and 3I (or 3I per cent.) of the malaria-treated patients were classed as " severe," while 70 (or 52 per cent.) of those treated with artificial fever and 55 (or 55 per cent.) of those treated with malaria were classified clinically as "intermediate." The average age of patients treated with artificial fever was 40 years and the average age of those treated with malaria was $42 \cdot 6$ years. The duration of symptoms prior to the institution of fever therapy was 22.8 months in the artificial fever therapy group and $17 \cdot 2$ months in the therapeutic malaria group.

During the first three years of this investigation the patients treated with artificial fever received 50 hours of fever at a rectal temperature of 105 to $106 \mathrm{~F}$. $(40 \cdot 6$ to 


\section{FEVER THERAPY}

$4 \mathrm{I} \cdot \mathrm{I} C$.), given as ten treatment sessions of five hours each. In the last two years of the study it was found that $a$ series of twelve individual fever sessions of three hours each (a total of 36 hours of fever) at a rectal temperature of $105.8 \mathrm{~F}$. (4I C.) was equally effective and had the decided advantage of permitting the treatment of a greater number of patients.

The extraordinary success of the Colorado investigators in following the progress of these patients is indicated by the fact that, with the exception of those who died, all of the malaria-treated cases and two-thirds of those treated with artificial fever during the preliminary study (reported in 1936) were followed during the entire five-year period. Most of those who disappeared were known to have responded favourably to fever-chemotherapy. The employment of skilled social workers, utilizing a rotating roster, was of great value in inducing patients to return for progress studies at intervals of six months following the completion of the course of chemotherapy subsequent to fever therapy.

Table II.-Dementia Paralytica: Types of Treatment and Clinical Results dURING Five-Year PERIOD

(Ewalt and Ebaugh, University of Colorado Psychopathic Hospital, Denver, Colorado)

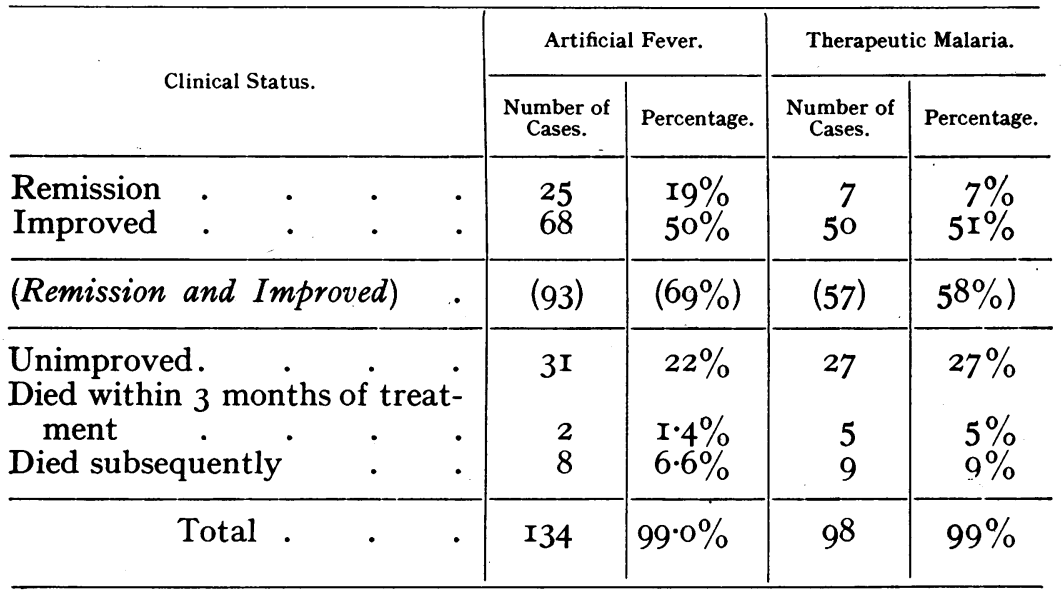

The clinical therapeutic results achieved by the Colorado workers are summarized in Table II. Of the 


\section{BRITISH JOURNAL OF VENEREAL DISEASES}

I34 paretic patients receiving artificial fever therapy, 25 (I9 per cent.) achieved remission, as compared with 7 ( 7 per cent.) of the 98 patients treated with malaria. Sixty-eight (50 per cent.) of those treated with artificial fever and 50 (5I per cent.) of the patients receiving therapeutic malaria were improved. The criteria used in determining " remission" and " improvement" were the same as those adopted by the Committee on NonSpecific Therapy of Syphilis, of the U.S. Public Health Service.

Thus, 69 per cent. of the patients treated with artificial fever were benefited, as compared with 58 per cent. of the malaria-treated patients. It is interesting to observe that approximately the same differences existed in the five-year series as in the one-year series described in the preliminary report by the same investigators. While the improvement rate and the relapse rate during the periods of post-therapy observation were approximately the same in the one-year and five-year studies, the differences appeared to be due to the better immediate response of patients treated with artificial fever. The authors express the belief that this difference may be due to the fact that with artificial fever the patients may be treated at higher temperature levels than is possible with malaria therapy. Another factor to which significance was attributed is that patients usually gained weight during the course of artificial fever therapy and in most instances were in distinctly better physical condition at the conclusion of the course. The patients treated with malaria, on the other hand, usually lost weight and developed varying degrees of anæmia despite energetic efforts to prevent these sequelæ.

The results obtained with either form of fever therapy, grouped according to the degree of severity of the paretic symptoms, are presented in Table III. As in the cooperative study made by the U.S. Public Health Service, the therapeutic results were best in "mild" paresis (45 per cent. of remissions with artificial fever and 25 per cent. with malaria therapy). Among those with "intermediate" symptoms and signs, 23 per cent. obtained remission following artificial fever therapy as compared with 7 per cent. of those who received therapeutic malaria. Full remission did not occur in any patient with " severe" paresis following either method 
Table III.-Dementia Paralytica: Classification of Clinical Groups in Relation to Clinical RESULTS

(Ewalt and Ebaugh, University of Colorado Psychopathic Hospital, Denver, Colorado)

\begin{tabular}{|c|c|c|c|c|c|c|c|c|c|c|c|c|}
\hline \multirow{3}{*}{ Clinical Status. } & \multicolumn{6}{|c|}{ Artificial Fever. } & \multicolumn{6}{|c|}{ Therapeutic Malaria. } \\
\hline & \multicolumn{2}{|c|}{ Mild. } & \multicolumn{2}{|c|}{ Intermediate. } & \multicolumn{2}{|c|}{ Severe. } & \multicolumn{2}{|c|}{ Mild. } & \multicolumn{2}{|c|}{ Intermediate. } & \multicolumn{2}{|c|}{ Severe. } \\
\hline & No. & $\begin{array}{l}\text { Per } \\
\text { cent. }\end{array}$ & No. & $\begin{array}{c}\text { Per } \\
\text { cent. }\end{array}$ & No. & $\begin{array}{c}\text { Per } \\
\text { cent. }\end{array}$ & No. & $\begin{array}{l}\text { Per } \\
\text { cent. }\end{array}$ & No. & $\begin{array}{l}\text { Per } \\
\text { cent. }\end{array}$ & No. & $\begin{array}{c}\text { Per } \\
\text { cent. }\end{array}$ \\
\hline $\begin{array}{l}\text { Remission } \\
\text { Improvement. } \\
\text { Unimproved } \\
\text { Died }\end{array}$ & $\begin{array}{r}9 \\
\mathbf{I} \mathbf{I} \\
0 \\
0\end{array}$ & $\begin{array}{r}45 \\
55 \\
0 \\
0\end{array}$ & $\begin{array}{r}16 \\
39 \\
12 \\
3\end{array}$ & $\begin{array}{r}23 \\
54 \\
17 \\
4\end{array}$ & $\begin{array}{r}0 \\
18 \\
19 \\
7\end{array}$ & $\begin{array}{r}0 \\
41 \\
43 \\
16\end{array}$ & $\begin{array}{l}3 \\
6 \\
1 \\
2\end{array}$ & $\begin{array}{r}25 \\
50 \\
8 \\
17\end{array}$ & $\begin{array}{r}4 \\
35 \\
I I \\
5\end{array}$ & $\begin{array}{r}7 \\
64 \\
20 \\
9\end{array}$ & $\begin{array}{r}0 \\
9 \\
\times 5 \\
7\end{array}$ & $\begin{array}{r}0 \\
29 \\
48 \\
23\end{array}$ \\
\hline Total & 20 & $100 \%$ & 70 & $98 \%$ & 44 & $100 \%$ & 12 & $100 \%$ & 55 & $100 \%$ & $3 I$ & $100 \%$ \\
\hline
\end{tabular}

of fever therapy. The proportions of "improved" patients were essentially the same with either mode of therapy, except that among the patients with " severe" paresis, 4I per cent. responded favorably to artificial fever therapy as compared with 29 per cent. of those receiving therapeutic malaria. Of the patients with " mild" paresis, all were benefited by artificial fever therapy and only one failed to respond favourably to malaria therapy.

None of those treated with artificial fever died during the course of fever therapy, while two died during malaria therapy. Two patients ( $\mathrm{I} \cdot 4$ per cent.) treated with artificial fever died within three months of treatment, as compared with five deaths (5 per cent.) during this interval among those treated with malaria. The number of subsequent deaths was not significantly different (8 patients, or 6.6 per cent., in the artificial fever group and 9 patients, or 9 per cent., in the therapeutic malaria group).

While marked clinical improvement was maintained in many individuals with persistently positive spinal fluid serology, there was an appreciably greater proportion of serologic reversals from positive to negative among those who experienced clinical remission or improvement. The spinal fluid serologic reactions were reversed to negative in II per cent. of those treated with artificial fever and in 6.I per cent. of those receiving 
therapeutic malaria. The reactions became less positive in 35 per cent. of those in the artificial fever therapy group and in 28.5 per cent. of the malaria-treated patients. The serologic reactions remained positive in 35 per cent. of those treated with artificial fever and in 40.8 per cent. of those who received malaria therapy. Eighteen per cent. of the patients who were treated with artificial fever and 24.4 per cent. of those who were treated with malaria were not available for final evaluation of cerebrospinal fluid serology. A large proportion of those who failed to return regularly for re-examination were known to have achieved a successful clinical result. Thus, of the Io9 patients treated with artificial fever who were available for repeated serologic re-examinations, 62 (or 57 per cent.) exhibited reversal or improvement in their serologic status; of the 74 malaria-treated patients subjected to adequate serologic study, 34 (or 46 per cent.) showed similar degrees of serologic improvement.

Ewalt and Ebaugh found that intensive chemotherapy subsequent to fever therapy is an essential requirement for sustained optimum results. These authors expressed the belief that the variations in therapeutic results reported from different clinics may well be due in large part to the degree of effort exerted in inducing patients to return at regular intervals for chemotherapy and for clinical and serologic re-examinations.

Finally, it is pertinent to observe that Ebaugh and Ewalt have now abandoned malaria therapy in favour of artificial fever therapy.

\section{Recent Reports by BennetT, et al., University of Nebraska, OMAHA}

The favourable experiences of Professor A. E. Bennett and his associates at the University of Nebraska, Omaha, with artificial fever therapy combined with chemotherapy in the management of the various stages of neurosyphilis have been described in five recent publications (5). One report (5c) deals with a review of a five-year experience in the treatment of dementia paralytica (G.P.I.) by this combined method at the University of Nebraska College of Medicine and at the Hastings (Nebraska) State Hospital. The apparatus employed for the production of fever was the Kettering hypertherm. Comparisons were made of 


\section{FEVER THERAPY}

the artificial fever-chemotherapy method with previous experiences in the use of chemotherapy alone (tryparsamide plus heavy metals) and in the employment of malaria inoculation followed by chemotherapy. The comparative incidence of remissions resulting from the use of these therapeutic programs is shown graphically in Chart I. It may be observed that the percentage of paretic patients achieving remission with artificial fever combined with and followed by chemotherapy (53 per cent.) was significantly greater than that which followed either malaria inoculation and subsequent chemotherapy (42 per cent.) or chemotherapy alone (I2 per cent.). The patients treated with artificial fever received 50 hours of fever (rectal temperature) above ro5 F. (40.6 C.), induced by means of the Kettering hypertherm, usually given in ten to fifteen 3 to 5 hour sessions. Chemotherapy during and subsequent to the fever sessions consisted of injections of 0.06 gram of mapharsen (meta-amino-parahydroxy-phenylarsine oxide), usually prèceded by concurrent injections of a bismuth salt (o.or gram). The malaria-treated patients received twelve chills, followed by tryparsamide and bismuth therapy, usually for several years. Those paretic patients who were treated with chemotherapy alone received adequate courses of tryparsamide and heavy metals (bismuth and mercury).

Particular mention should be made of a special group of I2 patients who had been committed to the Hastings State Hospital for periods of from one to five years because of advanced paretic dementia. All had received malaria therapy followed by long courses of tryparsamide and bismuth therapy. None achieved complete remission. The patients in this refractory group were then given a course of 50 hours of artificial fever combined with auxiliary mapharsen therapy. Four (or 33 per cent.) of those patients obtained complete remission, 3 (or 25 per cent.) were improved, while the remaining 5 patients were unaffected. Thus, 58 per cent. of those classed as malaria-failures were benefited by subsequent artificial fever therapy.

In addition to the 37 (or 53 per cent.) of the 70 patients treated with artificial fever combined with mapharsen therapy who exhibited remissions, there were 20 additional patients (or 28 per cent.) who were improved. Thus, $8 \mathrm{I}$ per cent. of the patients responded favourably. 


\section{BRITISH JOURNAL OF VENEREAL DISEASES}

The spinal fluid serologic reactions were reversed to negative in 24 patients (or 34 per cent.), and became less positive in 26 (or 37 per cent.).

Bennett and his associates $(5 \mathrm{a}, \mathrm{b}, \mathrm{e})$ have reported similarly favorable experiences in the treatment of asymptomatic neurosyphilis, tabes dorsalis, the tabetic form of dementia paralytica, and meningovascular neurosyphilis with combined artificial fever and chemotherapy. Of 8 patients with asymptomatic neurosyphilis, all of whom had had long-continued chemotherapy previously, the spinal fluid serologic reactions were reversed to negative in 5 patients, were less positive at the time of the last observation in 2 and were unchanged in one uncooperative patient who had only 29 hours of fever.

All of I2 patients with meningovascular neurosyphilis, of whom 8 had not responded to presumably adequate chemotherapy, were benefited. Four patients had hemiparetic features; 3 had palsies of the cranial nerves; 3 had aphasic, convulsive and confusional psychotic reactions; 3 had chronic headaches associated with increased intracranial pressure and meningitic phenomena; one had a syndrome simulating multiple sclerosis. Except in the cases of one patient with hemiplegia, and another with occasional convulsions, all were rid of their symptoms. Prompt and striking improvement was observed in the aphasic and meningitic symptoms. Because of the presence of vascular complications, many of these patients would have been unable to tolerate malaria therapy. The great advantage in controlling by physical means the height and the duration of the fever was particularly apparent in this group of patients.

In 25 patients with tabes dorsalis, the predominant symptoms were lightning pains and gastric crises in I7 patients, ataxia in 7 patients, and "cord bladder" in 2 patients. The clinical results included complete relief from symptoms in 18 patients (chiefly those with root pains); some degree of improvement in 5 and no improvement in 2 . One patient experienced recurrence of root pains; in another the disease progressed to dementia paralytica after a long period of apparent improvement.

As a result of these and other studies, the authors drew the following conclusions: that patients of advanced 
years or in poor physical condition, including those with such complications as hypertension or aortitis, can be treated with greater safety with artificial fever because the height and duration of fever can be controlled readily ; that the concurrent employment of artificial fever and chemotherapy increases therapeutic effectiveness; that the prescribed number of hours of fever are more easily obtained by physical methods ; that the results of treatment are definitely correlated with the height and duration of fever; that continuous hospitalization is not a requirement when artificial fever therapy is used except for those exhibiting severe psychotic manifestations ; that the relapse rate is lower with physically induced fever; that the mortality rate is less with artificial fever; that a significant proportion of neurosyphilitic patients who fail to respond to malaria therapy or who obtain only moderate degrees of improvement following such treatment are benefited by subsequent artificial fever therapy ; that certain patients who would not be accepted as candidates for malaria therapy may be benefited by judiciously applied artificial fever therapy; and that artificial fever therapy combined with chemotherapy is the most effective method of therapy now available for resistant asymptomatic neurosyphilis and for all forms of symptematic neurosyphilis.

\section{REPORT BY BROMBERG, WASHINGTON UNIVERSITY, ST. LOUIS}

Bromberg (6) has recently described his successful experiences in the treatment of various manifestations of neurosyphilis with artificial fever therapy (utilizing the Kettering hypertherm) combined with chemotherapy, during a three-year period. The therapeutic program employed by Bromberg was essentially similar to that used by Bennett, et al., and by Ewalt and Ebaugh (vide ut supra).

It is of more than passing import to observe that Bromberg and his skilled associates have treated over 300 patients with artificial fever therapy, many of whom were quite ill, without a single fatality.

Of 76 patients treated by Bromberg for various manifestations of neurosyphilis, there were $2 \mathrm{I}$ with dementia paralytica, I 4 with the tabetic form of dementia paralytica 
(taboparesis), 2I with tabes dorsalis, 8 with meningovascular neurosyphilis, and 12 with asymptomatic neurosyphilis. Eighteen of the 2I paretic patients (or 86 per cent.) were improved; 3 were not benefited. Of the I4 patients with the tabetic form of dementia paralytica, I 2 (or 85 per cent.) were classified as improved. Among the 2 I patients with tabes dorsalis, 18 (or 86 per cent.) responded favourably; relief of root pains and gain in weight were outstanding features of the clinical response of the tabetic patients. All of the 8 patients with meningovascular neurosyphilis experienced prompt and marked improvement. The spinal fluid serologic responses were uniformly good in all of the 12 patients treated for asymptomatic neurosyphilis.

\section{Reports by Trautman, U.S. Public Health Service,} U.S. Marine Hospital, New Orleans

In comprehensive reviews of the experiences in artificial fever therapy during the past six years at the U.S. Marine Hospital, New Orleans, Trautman (7) tells of the treatment of 985 patients (a total of 5,500 treatment sessions), with one death. One hundred and nine patients were treated for neurosyphilis. The apparatus employed was the Kettering hypertherm. Most of the patients had received routine chemotherapy in the Marine Hospital or elsewhere, with little or no benefit, prior to the institution of artificial fever therapy. Chemotherapy was employed by Trautman in conjunction with the fever sessions and was continued after the course of fever treatments was terminated.

Most of the patients admitted to the U.S. Marine Hospitals are officers and sailors of the merchant marine. Since these men receive free medical care from the U.S. Public Health Service, they must agree to remain under observation at the discretion of the medical officers. Thus, there is provided an exceptional opportunity to study the results of treatment under the more favourable circumstances of continuous hospitalization than is usually possible in general hospitals. The only disadvantage is that it is sometimes difficult to obtain data on the progress of such patients some years after the course of treatment. In a high proportion of cases, however, the patients have returned to the U.S. Marine 


\section{FEVER THERAPY}

Hospital at New Orleans or to some other U.S. Marine Hospital for such studies.

- Fourteen patients with dementia paralytica received an average total of 60 hours of fever, at a rectal temperature level of 104-105 F. $(40 \cdot 0-40 \cdot 6 \mathrm{C}$.). There were 2 patients who exhibited symptoms of "mild" paresis; one recovered completely; the other improved clinically but passed from observation. Of 8 patients with "intermediate" paresis, 6 obtained remissions and 2 were improved. There were 4 patients with " severe " paresis ; of these, one showed improvement; in one, the disease progressed ; in the other 2 , treatments were discontinued because of the severity of the disease and because of associated cardiovascular complications. Thus, of the I4 paretic patients, Io (or 7I per cent.) are known to have been benefited, while the outcome is not known in one additional case.

Eleven patients with tabes dorsalis received an average of 13 fever treatment sessions of five hours each, at a rectal temperature of 104-106 F. $(40 \cdot 0-4 \mathrm{I} \cdot \mathrm{I}$ C.), at intervals of one week. Of 5 patients with " mild" tabetic symptoms, 4 obtained complete symptomatic relief and the fifth patient was markedly improved. In one case of "intermediate" tabetic involvement there was no improvement. The 5 patients with "severe" tabetic symptoms were benefited in that they were relieved of the associated pains. Hence, Io (or 90 per cent.) of the II tabetic patients obtained some degree of clinical improvement. The spinal fluid serologic reactions were reversed to negative in 5 patients, and became less positive in 2.

There were I3 patients with meningeal, vascular, or combined meningo-vascular neurosyphilis. Of the 7 patients with meningeal involvement, all responded favourably; prompt relief of symptoms was usually observed after the first fever session. Three of the 4 patients with vascular neurosyphilis had complete symptomatic recovery, while the fourth had sufficient improvement to enable him to undertake light work. The 2 patients with meningo-vascular neurosyphilis were moderately improved. The spinal fluid reactions became negative in 7 of the 13 patients and were less positive at the time of last observation in 2 ; the serologic outcome in 2 patients is not known. The prompt response as

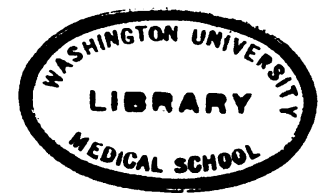


regards the disappearance of the meningitis symptoms and the restoration of the spinal fluid cell count and globulin content to normal levels were the outstanding features in this group. All were benefited by the treatment.

Seventy-one patients with asymptomatic neurosyphilis were treated by Trautman and his associates. Of the 45 patients in this group on whom adequate post-therapy observations were made, the spinal fluid serologic reactions were reversed to negative in 30 (or 66 and twothirds per cent.), while the remaining ${ }_{5} 5$ retained some degree of serologic positivity. The blood serologic reactions became negative in 29 . It is probable that the percentage of serologic reversals would have been greater if some of the patients had been observed over longer periods. None of the 45 patients, the outcome of whose treatment is known, has developed any evidence of clinical neurosyphilis.

\section{Recent Report of Neymann, Northwestern UNIVERSITY, CHICAGO}

To his many previous reports, Neymann (8) has contributed a recent summation of his experiences in the artificial fever therapy of syphilis since 1927. Neymann and his associates (Osborne, Koenig, Feinberg and Markson) have utilized electropyrexia (short wave diathermy currents, now applied in an air-conditioned cabinet) combined with chemotherapy (tryparsamide plus bismuth or mercury) in the treatment of 120 patients with dementia paralytica. Fifty-five (or 46 per cent.) achieved complete remission. In determining remission, Neymann included only those paretic patients who were not only rid of their symptoms, but who had also resumed their former or equivalent occupations and who had remained at work for at least six months. Twenty additional patients (or I7 per cent.) were improved. Thus, a total of 75 patients with dementia paralytica (or 63 per cent.) were benefited.

In a survey based upon the clinical results reported by some fifty investigators in the treatment with artificial fever of 975 patients with dementia paralytica, produced by a variety of physical methods, Neymann found that at least 266 (or 27 per cent.) had obtained remission, while 354 (or 36 per cent.) were improved. The recorded 
percentage of remissions is probably lower than the actual proportion, since Neymann included in this category only those patients in whom there was unequivocal evidence of remission. In sum, 620 of the 975 paretic patients (or 63 per cent.) were benefited by artificial fever therapy. In comparing these results with those attained with malaria therapy, Neymann stated that the use of artificial fever therapy increased the total rate of improvement in patients with dementia paralytica by $2 \mathrm{I}$ per cent., and decreased the treatment-death rate to an almost negligible level.

In a similar analysis of the reported clinical results obtained by I7 investigators utilizing several different physical modalities for the production of artificial fever in the management of tabes dorsalis, Neymann found that of II4 tabetics, 75 (or 66 per cent.) were improved. In his own series of 8 tabetics, all of whom improved, the disappearance of root pains was the outstanding feature of therapy. Tabetic crises and pains did not recur during periods of post-therapy observation extending from one to three or more years.

After I3 years of experience with artificial fever therapy and after extensive previous experience with malaria therapy, Neymann has come to regard the " mythical, unproved and much extolled magical action of the plasmodium of malaria" in the treatment of neurosyphilis as a "fetish or taboo in the minds of its most ardent advocates."

Reports by Hinsie and Blalock, New York State Psychiatric Institute and Hospital, New York

In addition to providing further evidence of the merits of artificial fever therapy, the reports by Hinsie and Blalock are of particular significance in that a careful analysis was made of the results obtained with artificial fever therapy alone, with artificial fever therapy followed by a course of 12 or more injections of tryparsamide and bismuth, and with artificial fever therapy combined with an injection of tryparsamide just prior to each fever treatment and followed by a course of tryparsamide after the conclusion of the course of combined fever-tryparsamide treatments. The apparatus employed by Hinsie and Blalock was the ultra high-frequency apparatus 
developed by Whitney, known as the " radiotherm." The data are based on a study of 146 adult patients with acquired dementia paralytica observed during a period of five and one-half years. The patients in each group received ten treatments at approximately I05 F. or $(40 \cdot 6 \mathrm{C}$.), each of seven hours' duration, on alternate days for the purpose of simulating the malarial character of the febrile course. At the end of the second year of posttherapy observation, the remission rate in the patients who received artificial fever therapy alone was 18 per cent. ; in those who received an equivalent amount of fever therapy followed by a course of tryparsamide therapy, the remission rate was 27 per cent. ; in those receiving injections of tryparsamide in conjunction with and following fever therapy the remission rate was 30 per cent. An additional 29 per cent. were improved following fever therapy alone, while the percentages of improvement in the other two groups were 36 and 35 . On the basis of these and other studies, Hinsie and Blalock expressed the beliefs that the employment of fever therapy alone produced results comparable to those obtained with malaria therapy and that much more favourable results are obtained when chemotherapy is employed in conjunction with artificial fever therapy.

In a recent communication (1938), Hinsie and Blalock have reported the serologic results of both blood and spinal fluid of patients treated for dementia paralytica with either malaria therapy or artificial fever therapy. The results are based on observations made in the same hospital during a four-year period. At the end of the fourth year, the blood serologic reactions were reversed to negative in 28 per cent. of the malaria-treated patients and in $59^{\circ}$ I per cent. of the patients treated with artificial fever; the spinal fluid reactions became negative in 57.2 per cent. of those treated with malaria and in 63.6 per cent. of those who received artificial fever therapy. These workers also observed that while serologic improvement is in general independent of the clinical response to either malaria or artificial fever therapy during the first few years after therapy, a persistently positive serologic ensemble after the third or fourth year following fever therapy has considerable prognostic significance since it is much more frequently associated with an unfavourable clinical outcome. 


\section{FEVER THERAPY}

In common with other investigators who have had extensive experience in the use of artificial fever therapy, Hinsie and Blalock have found no evidence that the relapse rate of paretic patients is higher with artificial fever therapy than with malaria therapy.

\section{Personal Experiences in the Treatment of NEUROSYPHILIS}

The history and progress of our work in artificial fever therapy since its inception in I93I has been recorded in several publications (I0). Impressed by the successful clinical results attained early in the course of the undertaking, despite the handicap of the inefficient physical modalities then available, we decided that future researches should be directed along two separate but related routes, namely, toward the development of simpler, safer and more easily controllable apparatus for the production of fever, and towards an exploration of the possible fields of usefulness for this mode of therapy.

After some years of experimentation with such modalities as hot baths, hot air cabinets, electric blankets, diathermy electrical currents and ultra high frequency electrical currents (radiotherm) we, with the indispensable collaboration of Dr. Charles F. Kettering and of $\mathrm{Mr}$. Edwin C. Sittler, ultimately devised an air-conditioned apparatus which fulfilled the requirements at which we had aimed. Eighty of these units were lent to 26 research centres for the purpose of widening the scope of the investigation. The physicians and nurses charged with the responsibility of administering the treatments properly in the various collaborating institutions received special training from us before the apparatus was released for their use.

Because the demands from other institutions exceeded our ability to supply them with this apparatus, an agreement was made with a reliable manufacturer of physical therapy apparatus (Liebel-Flarsheim Company, Cincinnati, Ohio) to manufacture the apparatus now known as the "Hypertherm" (Fig. I), under license of patents held by Dr. Kettering and the General Motors Corporation, without profit either to Dr. Kettering or to the General Motors Corporation. This apparatus is sold at 


\section{BRITISH JOURNAL OF VENEREAL DISEASES}

a reasonable cost only to qualified institutions (not to private practitioners) with the stated provision that the physicians and nurses who are to engage in the work must receive adequate preliminary training at an approved institution. During the past two and one-half years one or more hypertherms have been installed in qualified hospitals in the United States at the rate of one installation per week. Scores of other hospitals in this

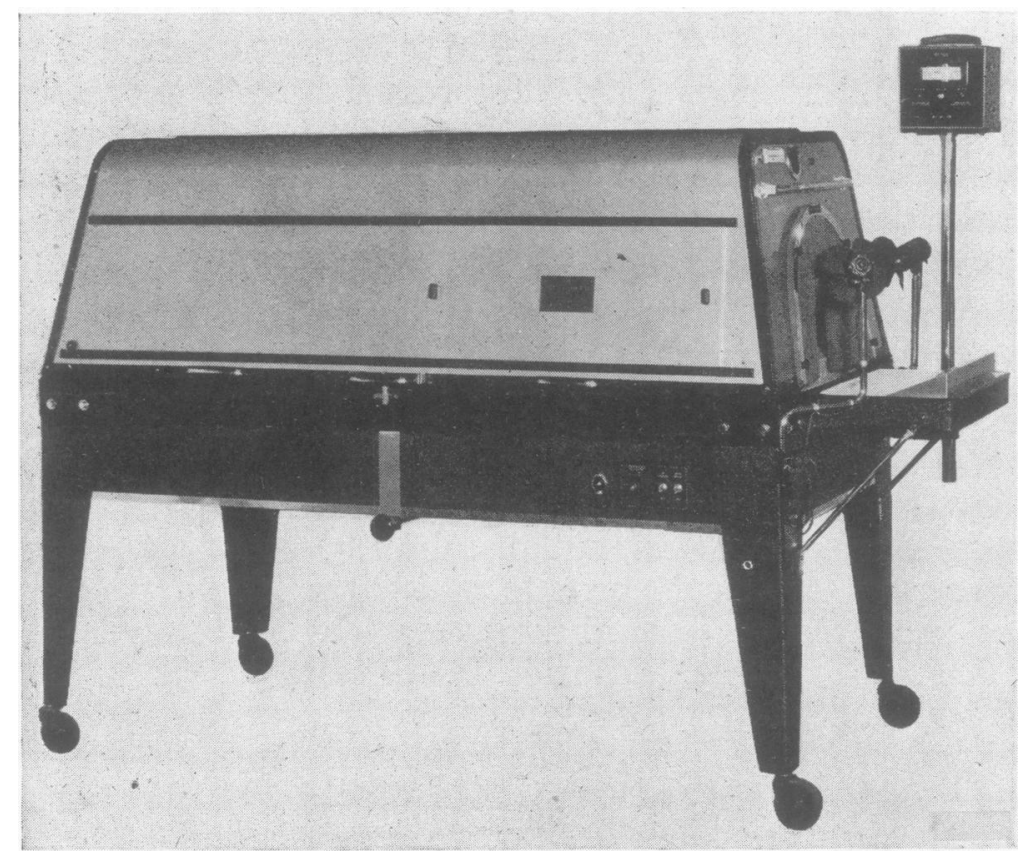

Fig. I. The Hypertherm.

country and abroad have installed other types of equipment for artificial fever therapy.

Coincident with the early engineering developments related to the apparatus, it was natural that the first clinical applications should be directed towards a determination of the possible usefulness of artificial fever therapy in the management of dementia paralytica. Wagner-Jauregg's successes with the treatment of this disease with malaria therapy had been widely confirmed. Comparable clinical results had also been obtained in those cases of dementia paralytica in which sustained high fever occurred following inoculations with 
the organisms of rat-bite fever and of relapsing fever, or following injections of vaccines prepared from typhoid and paratyphoid organisms or from Hamophilus ducreyi, or of heteroproteins such as milk or peptone, or of chemical substances such as sulphur. The early claims for specific, intrinsic merit in malaria inoculata appeared no longer to be tenable. Since the common denominator of this wide variety of agencies was the production of fever, many investigators (Neymann, Osborne, Bierman, Schamberg, Bessemans, Whitney, Carpenter, Warren, Kettering, the authors and others) were stimulated to search for safer and more easily controlled physical methods for accomplishing the same purpose.

Hence, the first patients treated by us with artificial fever, produced by means of various physical modalities, were those who were suffering from dementia paralytica. Despite the difficulties and discouragements encountered in the quest for suitable physical methods, it was observed from the start that the clinical results were at least comparable to those previously obtained by us and by others with malaria therapy.

Since the experiences of many workers with malaria therapy provided unmistakable evidence of the advantages of combining chemotherapy with malaria therapy, and since our results in a small group of patients treated with fever therapy alone were distinctly inferior we have utilized the combined fever-chemotherapy method practically from the outset.

One advantage of the artificial fever method in contract to malaria therapy is that arsenic and bismuth compounds may be administered with each fever treatment. Our observation (II) that fever appeared to exert a protective function against anaphylactic phenomena produced in sensitized individuals by arsenic, led us to change from the practice of injecting the arsenical compound half an hour before each fever treatment was begun to that of making the injection when the rectal temperature first reached the level of 105 F. (40.6 C.); this was ordinarily about 75 to 90 minutes after the fever session was started. By this procedure it is possible to abolish or to minimise greatly arsenical reactions in patients known to be highly sensitized to this substance.

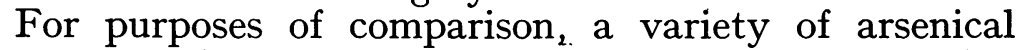
compounds has been employed (bismuth arsphenamine 


\section{BRITISH JOURNAL OF VENEREAL DISEASES}

sulfonate (bismarsen), tryparsamide, neoarsphenamine, or meta - amino - parahydroxy - phenylarsine oxide (mapharsen)). One significant observation has accrued from this comparative study, namely, that regardless of the type of arsenical compound used, and despite the great variation in arsenic content, the time required for clinical remission and for serologic reversal did not vary appreciably. Factors other than quantitative arsenic content appear to operate in producing a favorable outcome. During the past four years (since February, I937), we have utilized mapharsen (usually in individual doses of 0.06 grams) to the exclusion of other arsenical compounds. Our experiences confirm those of the many investigators who have found mapharsen to be less toxic than most other available compounds and to produce at the least equal clinical and serologic responses.

Just before each fever treatment was commenced the patient received an intramuscular injection of 4 grains of bismuth salicylate.

During the first six years of this investigation, the usual course of treatment for neurosyphilitic patients consisted of Io five-hour sessions of artificial fever therapy at I05-I06 F. (40.6-4I.I C.), with an optimum level of I05.8 F. (4I C.), usually at weekly intervals, for a total of fifty hours. This more or less arbitrary selection of height and duration of fever was based upon an analysis of the results which had been obtained with malaria therapy, which revealed that the proportion of remissions was greatest in those paretic patients who experienced approximately this amount of fever following malaria inoculation.

After the course of combined bismuth-arsenic-fever therapy was completed, the patients received an additional course of bismuth and arsenic injections, given concurrently, at weekly intervals for a period of 20 weeks.

The observation that most paretic patients appeared to experience maximum improvement after the first five or six five-hour fever sessions led us, in 1937, to experiment with a reduction in the total number of hours of fever together with a decrease in the number of hours per treatment. A comparison of clinical and serologic responses by both procedures revealed no essential differences. Consequently, the usual course of fever therapy during the past four years has consisted of 28 
twelve three-hour sessions at an average temperature level of $105.8 \mathrm{~F}$. (4I C.), or a total of 36 hours of fever therapy at this level. Furthermore, it has been found advantageous and equally efficacious to administer fever therapy at more frequent intervals. Thus, patients from distant cities who cannot commute at weekly intervals, were usually hospitalized and received three fever treatments during each week for four weeks. No difficulties have arisen from this program, either as a result of shortening the interval between treatments or from the more frequent administration of chemotherapy. Most of the patients were from Dayton or the immediate vicinity. Practically all of the local patients were treated on an ambulatory basis at semi-weekly or weekly intervals. The only exceptions were those who required continuous hospitalization during the course of treatment because of physical or mental complications. The advantages of this latter program of shorter sessions at more frequent intervals are that it is possible for one nurse-technician to treat two patients each day, it reduces the cost of the treatments, and it furthers the program of ambulatory care.

Individualization of the therapeutic program according to the status of the patient under treatment is of paramount importance. Most patients being treated for neurosyphilis can tolerate three hours of fever at I05Io6 F. $(40 \cdot 6-4 \mathrm{I} \cdot \mathrm{I} \quad$ C.) with no difficulty. Markedly debilitated patients, those in the upper age-brackets and those with manifestations of mental deterioration constitute a group which ordinarily would be considered to be poor risks for either malaria or artificial fever therapy. It has been our practice to administer artificial fever to such patients in shorter sessions at a lower temperature level in the beginning, increasing the height and length of fever as the course of treatment progresses. In this manner we have been able with minimal risk to afford a large group of patients the benefits of a course of artificial fever therapy combined with chemotherapy. By such individualization it has been possible to extend treatment to advanced tabetic patients and to deteriorated paretic patients in whom ordinarily little is to be expected in the way of clinical improvement. The results have fully justified the additional effort. For the first treatment they are subjected to one hour of fever at I02-I03 F. 


\section{BRITISH JOURNAL OF VENEREAL DISEASES}

$(38 \cdot 8-39 \cdot 4$ C. $)$. If this is well tolerated, the next treatment whether weekly or semi-weekly, is given for one hour at I03-I04 F. $\left(39^{\circ} 4-40^{\circ} \mathrm{C}\right.$ C.). The fever is increased during the next treatment to $104-\mathrm{IO}^{\circ} \mathrm{F}$. $(40 \cdot 0-40 \cdot 6 \mathrm{C}$.) and finally to $105-106 \mathrm{~F}$. $(40 \cdot 6-4 \mathrm{I} \cdot \mathrm{I} \quad \mathrm{C}$.). When the desired height is reached, the length of the fever session is gradually increased until we are able to give three hours of fever at I05-I06 F. (40.6-4I.I C.). If at any time the patient should display evidence of intolerance to the treatment, either the same length and height of fever or a shorter session at a lower temperature level is given at the next treatment. The average patient is usually able to tolerate the full three-hour session at 105-106 F. $(40 \cdot 6-4 I \cdot I$ C.) after three or four of the short sessions at lower levels. This individualization has been rendered more feasible by the improvements in apparatus and in technic.

Since I93I, we have subjected II39 patients to artificial fever therapy. Of this number, 376 patients have been treated for various manifestations of syphilis.* With one possible exception, no patient was harmed by the treatments save for the occasional occurrence of mild skin burns during the early phase of the work. With the improvements in the apparatus this hazard has been entirely eliminated. We have not observed a single instance of skin burn during the course of artificial fever treatments for over four years. Even erythema of the skin no longer occurs.

The single exceptional case in which death occurred was that of a 37 year-old man, who was suffering from fulminating meningovascular syphilis and rapidly progressing blindness due to optic atrophy. He had had hypertension for an undetermined period and the history suggested well-advanced cerebral vascular sclerosis. At the insistence of the patient and his physicians and with full recognition on the part of all concerned as to the unusual gravity of the situation, the patient was given cautiously a single fever treatment of four hours' duration. At the conclusion of the treatment his general condition was good. Seven hours later it was noted that he was somewhat confused and that there was beginning

\footnotetext{
* Most of the remaining patients were treated for gonococcic infection, certain forms of infectious arthritis, Sydenham's chorea, rheumatic fever, non-specific ocular infections, or undulant fever.
} 


\section{FEVER THERAPY}

paralysis of the right extremities. By the next morning the hemiparesis was complete and the patient lapsed into unconsciousness. He died the second day after the fever treatment, probably as the result of cerebral hæmorrhage. Permission for post-mortem examination was denied.

Only those patients who have been under observation for periods of from 18 months to 9 years and 4 months are considered in this report. Furthermore, the results of therapy as stated in this report refer only to the responses attained after a single course of combined artificial fever and chemotherapy. Those patients who did not improve following the usual course, but who attained varying degrees of improvement following a second course, will be considered separately.

The records of 75 syphilitic patients, or 20 per cent. of the total number of those treated for this disease, are incomplete as a result of the failure of these patients to return at regular intervals for clinical and serologic re-examinations for at least two years following the course of therapy. It is known that many of these persons were benefited, at least for periods of several months, by the course of treatment. Many of those who obtained improvement failed to return, despite the urgent pleas of physicians and social workers, because they could not be convinced that it was necessary. A majority of the patients have been observed at regular intervals for over four years.

Of 208 patients treated by us for neurosyphilis, the records of 43 or $(20.6$ per cent.) were excluded from consideration because of incomplete post-therapy observation. Thus, the records of 165 neurosyphilitic patients fulfil the necessarily rigid criteria for critical analysis. These include 65 patients with dementia paralytica, 27 with the tabetic form of dementia paralytica (taboparesis), 29 with tabes dorsalis, 6 with meningeal neurosyphilis, II with vascular neurosyphilis, 9 with meningo-vascular neurosyphilis and I8 with asymptomatic neurosyphilis (Table IV).

\section{(a) Dementia Paralytica}

The 65 patients treated for dementia paralytica were grouped according to the classification (described previously) adopted by the Committee on Non-Specific 
BRITISH JOURNAL OF VENEREAL DISEASES

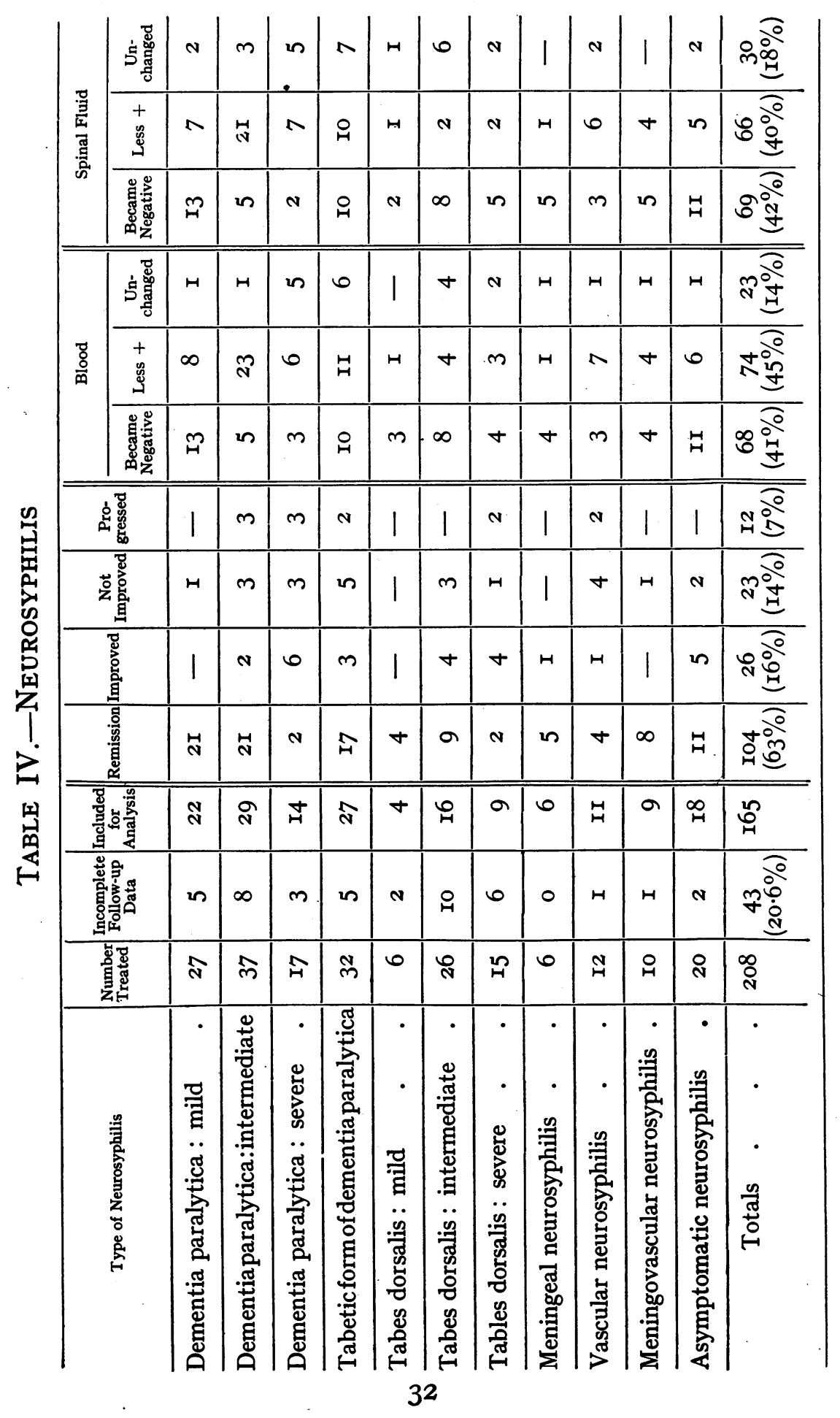




\section{FEVER THERAPY}

Therapy of Syphilis of the U.S. Public Health Service, as " mild," "intermediate," or " severe." Simularly, in the appraisal of the results of therapy, the criteria adopted by this Committee were employed. The median age of patients treated for dementia paralytica was $37 \cdot 8$ years. All but 15 of the 65 paretic patients had received presumably adequate chemotherapy prior to the institution of artificial fever therapy; the others had received insignificant amounts of chemotherapy or none.

Included for analysis were the clinical and serologic data on 22 patients with " mild" dementia paralytica. Further proof of the necessity for treating paretic patients during this early stage of the disease is found in the fact that 2 I of the 22 patients (or 95 per cent.) achieved remission; one patient was not improved. In those treated for " mild" paresis, the blood serologic reactions were reversed to negative in 13 patients (or 59 per cent.), became less positive in 8 additional patients (or 36 per cent.), and were not influenced in I patient (or 5 per cent.). The spinal fluid serologic reactions became negative in 13 patients (or 59 per cent.), were less positive at the time of last observation in 7 patients (or 32 per cent.), and remained positive in 2 patients (or 9 per cent.).

Of the 29 patients with "intermediate" dementia paralytica, 2I (or 72 per cent.) obtained remission; two patients (or 6 per cent.) were improved. Thus, 78 per cent. of those with " intermediate "paresis were benefited. Three patients in this group were not improved, and the disease progressed following treatment in 3 additional patients. The blood serologic reactions were reversed to negative in 5 patients (or I7 per cent.) of those with "intermediate" paresis, became less positive in 23 patients (or 79 per cent.), and remained positive in I patient (or 4 per cent.). The spinal fluid serologic reactions were changed to negative in 5 patients (or I7 per cent.), were less positive at the time of the last re-examination in 2I patients (or 73 per cent.), and remained positive in 3 patients (or Io per cent.).

As would be anticipated, the proportion of favourable clinical responses to the combined method of feverchemotherapy was distinctly less in the patients with " severe" paresis. Thus, of I4 patients in this advanced stage of the disease, only 2 (or I4 per cent.) achieved 


\section{BRITISH JOURNAL OF VENEREAL DISEASES}

clinical remission. Six additional patients (or 43 per cent.) were improved. In 3 patients there was no improvement, while in 3 others the disease progressed despite treatment. It is perhaps of importance to indicate, however, that even in patients with manifestations of advanced paresis considerable salvage was effected. Over one-half of the patients in this category were benefited. The responses of the blood and spinal fluid reactions exhibited no constant relationship to the clinical outcome. The reactions remained strongly positive in some who achieved clinical remission, and were reversed to negative in some in whom the disease process was either uninfluenced or progressed. The serologic reactions of the blood became negative in 3 patients (or 21 per cent.), became less positive in 6 patients (or 43 per cent.), and remained positive in 5 (or 36 per cent.). The spinal fluid serologic reactions were reversed to negative in 2 patients (or I4 per cent.), became less positive in 7 patients (or 50 per cent.), and were still positive at the time of the last observation in 5 patients (or 36 per cent.).

\section{(b) Tabetic Form of Dementia Paralytica (Taboparesis)}

In the group of 27 patients with the tabetic form of dementia paralytica (taboparesis) the symptoms and signs of paresis usually dominated the clinical picture. All but one had received varying amounts of chemotherapy prior to artificial fever therapy. While many of these patients achieved coincidental improvement in both tabetic and paretic manifestations, the clinical outcome of therapy was largely dependent upon the relative mildness or severity of the paretic symptoms. Since it was not considered feasible to classify such patients in " mild," " intermediate " or " severe " categories because of the great variation in the relative degrees of paretic and tabetic symptoms, they are considered as one group. The prompt relief of lightning pains and gastric crises was the outstanding feature of the response to treatment ; 3 patients experienced recurrence of root pains which yielded to additional fever-chemotherapy. Those with ataxia of short duration usually experienced some improvement in gait. Three patients with "cord bladder" regained control of bladder function; one 


\section{FEVER THERAPY}

advanced taboparetic with "cord bladder" was not benefited.

Seventeen of the 27 taboparetic patients (or 63 per cent.) achieved clinical remission of both tabetic and paretic symptoms. Three additional patients (or II per cent.) were improved. Thus, 20 of the 27 patients (or 74 per cent.) in this group responded favourably. Five patients with severe paretic symptoms were not improved and the disease progressed during and after treatment in two demented patients, who died six months and one year, respectively, after the course of treatment was completed.

The blood serologic reactions were reversed to negative in Io patients (or 37 per cent.), became less positive in II patients (or 4I per cent.), and were not influenced in 6 patients (or 22 per cent.). The spinal fluid serologic reactions were reversed to negative in ro patients (37 per cent.), became less positive in Io patients (37 per cent.), and remained unchanged in 7 patients (or 26 per cent.).

\section{(c) Tabes Dorsalis}

All of the 29 patients with tabes dorsalis had received varying amounts of chemotherapy before artificial fever therapy was begun. Included in this group of patients were 4 with " mild" tabetic manifestations,* such as lightning pains of recent origin, paresthesias, pupillary disturbances, reduced or exaggerated reflexes, or diplopia. There were I6 patients with "intermediate" tabes dorsalis, in which group were included those manifesting such signs and symptoms as those mentioned above, together with such additional evidences as " cord bladder," early and mild ataxia, gastric crises, or early optic atrophy. The 9 patients with "severe" tabes dorsalis exhibited such manifestations as marked ataxia, severe lightning pains or gastro-intestinal crises or both, incoordination, "cord bladder," marked hyperesthesias or paresthesias, optic atrophy, or Charcot joints. Most of the patients with " severe" tabes dorsalis presented themselves with evidences of advanced malnutrition and avitaminosis; many verged on starvation because of almost uninterrupted gastro-intestinal crises. These

* Classification of Committee on Non-Specific Therapy of U.S. Public Health Service. 


\section{BRITISH JOURNAL OF VENEREAL DISEASES}

patients presented the most trying treatment problems. Most would not have been considered as candidates for either malaria therapy or artificial fever therapy a few years ago. With the improvements in the apparatus for the production of fever and in the technic of administering the treatments, a significant proportion of these patients may be helped, particularly as regards relief from the lightning pains or from the gastro-intestinal crises. Such patients are first given short trial fever treatments, at a low fever level, following three or four of which it is usually possible to give the usual three-hour sessions at I05.8 F. (4I C.). Correction of dietary deficiencies, of anæmia, and often of narcotic addiction, are essential requirements in the therapeutic program.

It is unfortunate that the use of fever therapy is still too often regarded as a final, resortive method of treatment. Much better results will be achieved when it is more generally recognized that fever therapy combined with chemotherapy is the primary treatment of choice in all types of symptomatic and asymptomatic neurosyphilis. This fact is particularly apparent in the management of patients with tabes dorsalis.

Of the 4 patients with " mild" tabes dorsalis, all obtained prompt and lasting remission. The lightning pains or gastro-intestinal crises, or both, often responded after the first two or three treatments. There has been no recurrence of such pains in the patients with " mild " tabetic symptoms; additional treatments were not required in this group of patients. The blood serologic reactions of the "mild" tabetic patients were reversed to negative in 3 patients (or 75 per cent.) and in the fourth patient (or 25 per cent.) became less positive. The spinal fluid serologic reactions became negative in two patients (or 50 per cent.), were less positive at the time of the last re-examination in I patient (or 25 per cent.), and remained unchanged in I patient (or 25 per cent.).

Nine (or 56 per cent.) of the 16 patients with " intermediate" tabes dorsalis obtained clinical remission following one course of combined fever-chemotherapy. The most striking result of treatment was the prompt and persistent disappearance of the lancinating pains and gastro-intestinal crises. Three patients with mild and early ataxia were restored to normal gait. Four (or 25 per cent.) of the patients with "intermediate" tabes 


\section{FEVER THERAPY}

dorsalis obtained improvement. Three of these patients experienced recurrence of root pains, which were controlled with additional fever-chemotherapy. Two patients with " cord bladder" regained normal control of bladder function. Some improvement in gait disturbance occurred in all of the patients in this group. Three patients (or I9 per cent.) with " intermediate", tabes dorsalis were not benefited by the course of treatment. The blood serologic reactions were reversed to negative in 8 (or 50 per cent.) of the patients with "intermediate" tabes dorsalis, became less positive in 4 patients (or 25 per cent.) and were uninfluenced in 4 patients (or 25 per cent.). The spinal fluid serologic reactions were reversed to negative in 8 patients (or 50 per cent.), became less positive in 2 patients (or 12.5 per cent.), and were unchanged in 6 patients (or 37.5 per cent.).

The results of treatment were decidedly inferior in the group of 9 patients with "severe" tabes dorsalis. Remission occurred in only 2 patients (or 22 per cent.). Some measure of improvement, including relief of pains or improvement in bladder function, occurred in 4 patients (or 22 per cent.). In one patient there was no improvement. In 2 advanced tabetic patients the disease progressed despite treatment and these patients died of the disease several months after the completion of the course of treatment. The blood serologic reactions became negative in 4 patients (or 45 per cent.), became less positive in 3 patients (or 33 per cent.), and were unchanged in 2 patients (or 22 per cent.). The spinal fluid serologic reactions were reversed to negative in 5 patients (or 56 per cent.), were less positive at the time of the last reexamination in 2 patients (or 22 per cent.), and remained unchanged in 2 patients (or 22 per cent.).

\section{(d) Meningeal Neurosyphilis}

Six patients with meningeal neurosyphilis were treated with combined artificial fever therapy and chemotherapy. All but one had had presumably adequate chemotherapy. The characteristic manifestations of syphilitic meningitis were present, such as headache, dizziness, diplopia, nausea, vomiting, nuchal rigidity, aphasia, or convulsions, associated with the typical spinal fluid changes (pleo- 


\section{BRITISH JOURNAL OF VENEREAL DISEASES}

cytosis, increased protein content and strongly positive serologic reactions). Five of the 6 patients (or 83 per cent.) experienced complete clinical recovery ; the sixth patient was relieved of all symptoms and signs except residual diplopia. The spinal fluid cell count was promptly reduced to normal levels in all ; the protein content of the spinal fluid exhibited a similar but invariably slower reduction to normal levels. The blood serologic reactions were reversed to negative in 4 patients (or 67 per cent.), became less positive in one patient and remained positive in another. The spinal fluid serologic reactions were favourably influenced in all; there was reversal to negative in 5 (or 83 per cent.) and reduction in positivity in one (or I7 per cent.).

\section{(e) Vascular Neurosyphilis}

Twelve patients received combined artificial fever and chemotherapy because of vascular neurosyphilis. The records of II patients are complete to date; the twelfth patient disappeared shortly after having attained an apparently favorable response to treatment. Of the II patients whose records are included in the analysis, all but one had received presumably adequate, but ineffectual, chemotherapy prior to the institution of artificial fever therapy.

The patients classified as having vascular neurosyphilis did not present evidence of meningeal involvement, but presented such subjective and objective manifestations of vascular neurosyphilis as headaches, dizziness, monoplegia, hemiplegia, aphasia, recurrent cerebrovascular accidents in the absence of evidence of arteriosclerosis, or convulsions, together with characteristic spinal fluid changes.

Of the 4 patients (or 36 per cent.) who achieved complete remission, 2 had experienced cerebrovascular accidents followed by transient hemiplegia; there has been no recurrence in either patient during the 3 and 5 year intervals which have elapsed since fever-chemotherapy was given. One patient was improved, but some residual hemiplegia has persisted. Four patients (or 36 per cent.) were not improved, while in 2 other patients (or I8 per cent.) the disease progressed. The blood serologic reactions were reversed to negative in 


\section{FEVER THERAPY}

3 patients (or 27 per cent.), became less positive in 7 patients (or 63 per cent.), and remained positive in one patient. The spinal fluid serologic reactions became negative in 3 patients (or 27 per cent.), were less positive at the time of the last re-examination in 6 patients (or 55 per cent.), and have remained positive in 2 patients (I8 per cent.).

\section{(f) Meningovascular Neurosyphilis}

The 9 patients with meningovascular neurosyphilis whose records are complete exhibited various combinations of meningeal and cerebrovascular manifestations. In some, the vascular component was predominant while in others the meningeal involvement was more pronounced. The meningitic phenomena were promptly and favorably influenced in all. Eight of the 9 patients (or 89 per cent.) achieved complete clinical remission; the other patient experienced no improvement in the hemiparesis which had developed 3 months before artificial fever treatment was begun. The blood serologic reactions were reversed to negative in 4 patients (or 44 per cent.), became less positive in 4 patients (or 44 per cent.), and were unchanged at the time of the last re-examination in one patient. The spinal fluid serologic reactions became negative in 5 patients (or 56 per cent.) and became less positive in 4 patients (or 44 per cent.).

\section{(g) Asymptomatic Neurosyphilis}

It is now generally recognized that the best time to treat neurosyphilis with fever-chemotherapy is when the disease is first recognized in its asymptomatic phase. The now more common and eminently desirable practice of performing spinal fluid examinations before, during and after the course of antisyphilitic chemotherapy, has provided indisputable evidence of the high incidence of neurosyphilis. The extensive and carefully documented coöperative clinical studies made by Stokes, Cole, Moore, O'Leary, Wile, Clark, Parran and Usilton (I2a, b, c) revealed that abnormal spinal fluid conditions were present in 33 per cent. of patients with early syphilis, and in $56 \cdot \mathrm{I}$ per cent. of patients with late secondary 


\section{BRITISH JOURNAL OF VENEREAL DISEASES}

syphilis. The same observers have also stated that " even thoroughgoing (chemical) treatment does not necessarily prevent the development of abnormalities of the spinal fluid" (I2b) and that in latent syphilis "almost all the serologic response to be expected occurs within the first four months of treatment; thereafter, further (chemical) treatment has little effect" (I2C). In our experience, the favourable response to combined artificial fever-chemotherapy has been most prompt in those patients who were referred to us for such treatment immediately after the diagnosis of asympto- matic neurosyphilis was first established. All but 4 of our patients with asymptomatic neurosyphilis had had presumably adequate chemotherapy. No patients with so-called "Group I" spinal fluid changes (slight to moderate pleocytosis and increase of protein, with negative serologic reactions and negative colloid gold curves) are included in our series.

In the I8 patients with asymptomatic neurosyphilis treated by us with artificial fever-chemotherapy, who have been observed at intervals for a sufficiently long period, the spinal fluid serologic reactions, cell count and protein content have been restored to normal in II patients (or 6I per cent.). The serologic reactions of the spinal fluid showed a declining trend at the time of the last observation in 5 additional patients (or 28 per cent.). Thus, there was improvement in the serologic status of I6 (or 89 per cent.) of these patients. In the remaining 2 patients (or II per cent.), the spinal fluid reactions were still positive at intervals of 20 months and 27 months, respectively, following the termination of the course of treatment. On the basis of prior experience, there is reason to anticipate that those patients who now exhibit a declining trend in serologic positivity and that those more recently treated patients whose reactions are still positive, will ultimately obtain a successful result. No patient who achieved serologic reversal has experienced either serologic relapse or any evidence of symptomatic neurosyphilis.

The responses in the blood serologic reactions closely paralleled those in the spinal fluid. An equal number of patients (II, or 6I per cent.) achieved negativity. Six additional patients (or 33 per cent.) exhibited less positive reactions, while one more recently treated patient had 
unchanged positive reactions at the time of the last observation.

It seems axiomatic to state, therefore, that the best treatment for neurosyphilis is to detect it in its incipiency and to prevent the later development of its disastrous consequences by the prompt administration of some form of fever therapy combined with chemotherapy.

In sum, it is interesting to note that the remission rate of all of the 165 well-documented cases of various types of neurosyphilis was 63 per cent. An additional 16 per cent. of patients were improved by the treatment. Thus, a total of 79 per cent. of the patients were benefited.

\section{OCUlar SyphiLIS}

One of the disastrous consequences of syphilis is blindness. This disease has been held responsible for at least Io per cent. of blindness occurring throughout the world. The various exhibitions of syphilis in the eye rank with those of neurosyphilis in their reluctance to respond to orthodox chemotherapy. Similarly, exudative, as opposed to degenerative, ocular syphilis responds in much the same favourable manner as neurosyphilis.

In many cases the ocular manifestations of syphilis are but one associated incident in patients with secondary syphilis, neurosyphilis, visceral syphilis, cutaneous syphilis, or osseous syphilis. Hence, in the cases studied by us, 63 of the Io3 patients with ocular syphilis (or 6I per cent.) had associated manifestations of syphilis elsewhere in the body, chiefly in the central nervous system.

The fact that a high proportion of patients with ocular syphilis have failed to respond to vigorous, continuous chemotherapy (arsenical, bismuth, mercurial and iodide compounds) had engendered an attitude of pessimism in the minds of many ophthalmologists and syphilologists. Such a spirit of hopelessness and indecision is no longer justified. Similarly, procrastination with chemotherapy may often rob the patient with ocular syphilis of his chance for the preservation of useful vision.

Following the advent of malaria therapy it was soon apparent that considerable salvage could be accomplished in cases of refractory ocular syphilis. Typhoidparatyphoid vaccine and other foreign protein substances 


\section{BRITISH JOURNAI OF VENEREAL DISEASES}

have also been used widely; even though favourable clinical responses have often followed the use of these fever-producing agencies, severe reactions have occurred, the febrile response is uncertain and is frequently inadequate. Many of our patients with ocular syphilis who had not been benefited by repeated injections of typhoid or T.A.B. vaccine responded well to subsequent artificial fever therapy.

Of the IO3 patients treated by us for various manifestations of ocular syphilis, I9 failed to return regularly for clinical and serologic re-examinations. The syphilitic ocular diseases of the 84 patients were classified as follows : exudative uveitis, Io patients ; neuroretinitis and optic neuritis, I3 patients ; choroiditis, Io patients ; interstitial keratitis, 2I patients ; optic atrophy, 25 patients; and extra-ocular palsy, 5 patients.

\section{(a) Exudative Uveitis}

All of the ro patients with exudative uveitis had received chemotherapy previously. In 6 instances the uveitis occurred while the patients were receiving continuous antisyphilitic therapy. Two patients had received intravenous injections of typhoid vaccine without benefit. In 7 of the patients there was so much exudate in the anterior segment that it was impossible to distinguish details of the fundus. Major impairment of vision seemed inevitable in all. After the first or second fever treatment there was distinct diminution in the degree of ciliary injection and in the amount of exudate, accompanied by improvement in the dilatation of the pupil and in relief of symptoms.

There was marked clinical improvement in 7 (or 70 per cent.) of the Io patients. The response in these patients was rapid and residual visual defects were either absent or were of minor degree. In the 3 remaining patients (or 30 per cent.), the inflammatory manifestations responded promptly; but there remained varying degrees of visual impairment. All, however, retained useful vision. There have been no recurrences.

McGavic(I3) has reported similarly favourable responses in II patients with iridocyclitis treated with artificial fever therapy (Kettering hypertherm) combined with chemotherapy. 


\section{FEVER THERAPY}

\section{(b) Optic Neuritis and Neuroretinitis}

In 2 of the I3 patients with optic neuritis and neuroretinitis this ocular complication occurred while they were receiving chemotherapy for secondary syphilis. Eight patients had some form of syphilis of the central nervous system. All but 2 had received varying amounts of chemotherapy. As in the cases of uveitis, there was prompt diminution in the amount of exudate in the fundus. Two patients had associated choroiditis and one also had exudative uveitis which responded equally well. All of the patients in this group recovered useful vision, although 8 retained some residual pallor of the disc and slight contraction of the visual fields. Active neuritis along the optic tract appears to be arrested by fever therapy.

\section{(c) Choroiditis}

The manifestations of choroiditis responded promptly in the Io patients with this ocular complication of syphilis. All had failed to respond to chemotherapy. The average time for the disappearance of the exudate was six weeks, which was somewhat longer than in the cases of uveitis and neuro-retinitis. Fortunately, none of the lesions involved the macula; hence, central vision was retained in all. Recurrence of choroiditis has not been observed in these patients following the course of combined fever-chemotherapy.

\section{(d) Interstitial Keratitis}

The ages of the 2 I patients suffering from interstitial keratitis varied from 8 to 38 years. All but 4 had been treated unsuccessfully with chemotherapy before fever therapy was instituted. Nine patients had experienced from one to eight previous attacks. The response to combined fever-chemotherapy was most prompt and favorable in those cases in which an opaque central disc of plastic exudate was present. It is usually this type of the disease which produces the greatest visual damage because it commonly leaves the center of the cornea permanently and densely opaque. While there was prompt relief of pain, blepharospasm, lacrimation and photophobia, the clearing of the corneal stroma occurred more slowly. The response was best in the acute stage of the disease and when there was considerable exudation 


\section{BRITISH JOURNAL OF VENEREAL DISEASES}

into the corneal stroma. While varying amounts of corneal scarring were present in several patients, depending largely upon the duration of the disease and the number of prior recurrences, there was little doubt that the more prompt resolution of the active inflammatory phase of the disease by fever therapy minimized the extent of the residual scarring. Only one patient has experienced a mild recurrence of interstitial keratitis, which responded promptly to additional fever-chemotherapy. Hence, it was concluded that the duration of this disease and the tendency towards recurrence are distinctly lessened following adequate artificial feverchemotherapy.

\section{(e) Optic Atrophy}

Optic atrophy occurred chiefly as an accompaniment of tabes dorsalis, or less often, of dementia paralytica. The visual acuity and the visual fields have remained practically unaltered following fever-chemotherapy in the 25 patients with optic atrophy. Since, without treatment, blindness often results within two or three years of the onset of primary optic atrophy, it is significant that the progression of the disease was apparently retarded by fever-chemotherapy. There is also some justification for the impression that if optic atrophy is associated with foci of active inflammatory infiltrations along the optic tract, such exudative lesions will respond to fever therapy.

Moore (I4) expressed the belief that fever therapy is especially of value when the optic atrophy is associated with paresis or taboparesis. In an analysis of the results obtained by II different observers, Moore found that of 89 patients treated with fever therapy, the optic atrophy improved or remained stationery in 39 per cent. and was unimproved or progressed in 6I per cent. Menagh (I5) found that 4 of Io patients with optic atrophy experienced visual improvement following artificial fever therapy combined with fever therapy.

\section{(f) Extra-Ocular Palsy}

Of the 5 patients with extra-ocular palsy, only 2 patients showed any degree of improvement following fever-chemotherapy, while 3 were not benefited. There was no evidence, therefore, that artificial fever therapy is 


\section{FEVER THERAPY}

superior to older methods of treatment in cases of extraocular palsy.

From the observations made on patients with ocular syphilis, it seems apparent that those syphilitic lesions which are characterized by exudate respond promptly and well to combined artificial fever-chemotherapy. In the interest of preserving vision, patients presenting such exudative manifestations should receive fever-chemotherapy as soon as possible after the diagnosis is established.

\section{Resistant Sero-Positive Latent Syphilis}

In an effort to determine the effect of artificial fever combined with chemotherapy on persistently positive blood serologic reactions, $5 \mathrm{I}$ patients with so-called "Wassermann-fast" latent syphilis have received the same course of combined therapy as that used for neurosyphilis (Table VI). All had had presumably adequate chemotherapy for at least two years. The records of 7 patients are incomplete; only those patients who were observed for at least two years following the completion of the combined course of fever-chemotherapy are considered in this analysis. Of the 44 patients whose records are satisfactory for analysis, I7 had had syphilis for from 2 to 4 years, while the remaining 27 patients had had the disease more than 4 years. The spinal fluid serologic reactions in all were negative. Of the I7 patients with early latent syphilis with resistant seropositive reactions, the blood serologic reactions were reversed to negative in $I 2$ patients (or 70 per cent.) and became less positive in 5 patients (or 30 per cent.). Of the 27 patients with seropositive late latent syphilis, the blood serologic reactions were reversed to negative in I3 patients (or 50 per cent.), became less positive in ro patients (or 38 per cent.), and remained positive in 4 patients (or I2 per cent.). No patient who achieved serologic reversal has exhibited either serologic or clinical relapse.

\section{Experimental Treatment of EARLy Syphilis With Combined Fever-Chemotherapy}

Before entering upon any discussion of the possible application of artificial fever therapy combined with 


\section{BRITISH JOURNAL OF VENEREAL DISEASES}

chemotherapy to primary and secondary syphilis it would be pertinent to emphasize the purely experimental character of the undertaking. While the results attained by other workers and by us are sufficiently encouraging to justify, or even to demand, continued and vigorous inquiry over a period of several years, it should not be inferred that this mode of therapy is recommended as a general substitute for the tried-and-proved scheme of continuous chemical treatment.

Candor requires, however, that recognition be given to the fact that even the generally approved methods of continuous chemical therapy possess serious, and often insuperable, handicaps. Not the least of these are the strong social and economic forces which now operate to keep large numbers of persons with early syphilis from receiving adequate therapy. A wholesome dissatisfaction exists even among syphilologists with the present orthodox methods of treatment. Because of the long period required for efficient treatment, the high cost and the not insignificant number of instances of chemical intoxication, the great majority of syphilitic persons do not receive even sufficient treatment to render them noninfectious to others (I6). There is convincing evidence that insufficient chemical treatment early in the course of syphilis prevents the development of the natural specific resistance to the disease. To quote Chesney (I7) : "A small amount of treatment in early syphilis is worse than none, precisely because it interferes with the body's own defensive mechanism while at the same time it often fails to eliminate the infection." Padget's (I8) longterm evaluation of the results of treatment of early syphilis at the Johns Hopkins Hospital led him to state that " the palpable inferiority of irregular and intermittent treatment strongly suggests that, if continuous treatment cannot be given, no treatment is the desideratum."

The deficiencies in the present-day management of syphilis have been stated succinctly and with admirable frankness by Moore (I9) : "It must be recognized that even given more clinics, better clinics and free clinics, the control of syphilis by present-day treatment methods is still far from satisfactory. Treatment is too prolonged, too painful, too dangerous, too expensive. Efforts of investigators to develop better and especially shorter methods of treatment should be encouraged." 


\section{FEVER THERAPY}

A rich background of experimental studies of animals and of human subjects, notably those made by Weichbrodt and Jahnel (20), Bessemans (2I), Schamberg and Rule (22), Carpenter, Boak and Warren (23), Levaditi and de Rothschild (24), Kolmer (25), and Simpson (Io $\mathrm{m}$ ), provides convincing evidence of the unfavourable influence of high body temperature upon Spirochata pallida. Bessemans and his associates found that the application of heat to the testicular syphilomata of rabbits, whether by means of hot water baths, hot air blowers, hot paraffin baths or packs, luminous or infrared radiations, electromagnetic induction or air-conditioned chambers, destroyed the spirochæte when the temperature in the syphilitic lesion (as measured by small thermocouples) was maintained at one hour at ro7.6 F. (42 C.), or for two hours at ro4 F. (40 C.).

Both Schamberg and Bessemans have commented upon the implications of such observations as regards the probable prophylactic value of a prolonged hot bath shortly after exposure to venereal infection. (The gonococcus is even more susceptible to heat).

Bessemans also found, however, that Spirochata pallida in the popliteal lymphnodes of a syphilitic rabbit rarely lose their-virulence if they are subjected only to a sufficiently high body temperature to destroy the spirochætes in the external lesions. It sometimes required a temperature of II $4 \cdot 8 \mathrm{~F}$. ( $46 \mathrm{C}$.) for one hour to achieve the same result.

On the other hand, Carpenter and his confrères found that body temperature of $106 \cdot 7-107 \cdot 6 \mathrm{~F}$. $(4 \mathrm{I} \cdot 5-42 \mathrm{C}$.), maintained for 6 hours, was uniformly sufficient to destroy Spirochata pallida both in the testicles and in the popliteal lymphnodes of syphilitic rabbits. Our animal experiments confirm these findings (Io h). It is well to point out that the in vivo thermal death time of Spirocheta pallida will vary with both the height and the duration of temperature. Thus, since the effect is one of thermal gradient, it is erroneous to state that any given temperature level is the thermal death time without adding a qualification as to the length of time the tissue containing the organism was exposed to that temperature. Hence, the in vivo thermal death time of Spirochata pallida in the popliteal lymphnodes of syphilitic rabbits is either II $4.8 \mathrm{~F}$. ( $46 \mathrm{C}$.) when the temperature is applied 


\section{BRITISH JOURNAL OF VENEREAL DISEASES}

for one hour (Bessemans), or I06.7-107.6 F. (4I.5-42 C.) when this range of temperature is maintained for 6 hours (Carpenter, Boak, and Warren ; Simpson and Kendell). Carpenter, et al., have also demonstrated that the same spirochætocidal effect is produced at lower temperature levels when applied for longer intervals.

More recently, both the Ghent investigators (Bessemans, et al.) and the Rochester workers (Boak, Carpenter and Warren) have performed independently a series of crucial experiments on the concurrent treatment of experimental syphilis in rabbits with artificial fever combined with chemotherapy. When his important work was interrupted by the invasion of Belgium, Professor Bessemans was in the midst of determining whether or not a judicious combination of chemotherapy and artificial fever therapy might be more effective than either form of therapy used alone in curing syphilis in rabbits. The preliminary experiments revealed that while some lymphnode transfers made from rabbits which had received either chemotherapy alone or artificial fever therapy alone caused the production of syphilis in normal rabbits, all of the lymphnode transfers from rabbits treated with combined fever-chemotherapy yielded entirely negative results.

The carefully conceived and admirably controlled recent experiments of Boak, Carpenter and Warren (26) were designed to determine the effects produced by combining subcurative chemotherapy with subcurative artificial fever therapy in experimental syphilis of rabbits. Notwithstanding the fact that many investigators (Kyrle (27), Richet and Dublineau (28), Simpson and Kendell (Io h, m), Neymann, Lawless, and Osborne (29) ) have found convincing clinical and immunologic evidence that fever therapy combined with chemotherapy is more effective than either agent employed singly, in the treatment of early syphilis in human beings, the Rochester investigators felt that additional experimental data were needed to establish the combined method as an accepted therapeutic procedure for early syphilis in human subjects. Two strains of Spirochata pallida, the Nichols and the Zinsser-Hopkins strains, were employed. Syphilis was produced in chinchilla rabbits by intratesticular injections of a suspension of spirochætes (confirmed by dark-field examination) derived by trituration in a mortar 


\section{FEVER THERAPY}

of tissue from the testes and from the popliteal lymphnodes of animals presenting prominent syphilitic lesions.

Table V.-EFfects on Experimental Syphilis in Rabbits of Concurrent Treatment With NeoARSPHENAMINE AND ARTIFICIALly INDUCED FEVER AT $106 \cdot 7^{\circ} \mathrm{F}$. $\left(4 \mathrm{I} \cdot 5^{\circ} \mathrm{C}\right.$.).

(Boak, Carpenter and Warren, University of Rochester, Rochester, New York

Experiment I :

\begin{tabular}{|c|c|c|c|}
\hline Treatment. & $\begin{array}{l}\text { Number } \\
\text { of } \\
\text { Animals. }\end{array}$ & $\begin{array}{l}\text { Number } \\
\text { Cured. }\end{array}$ & $\begin{array}{l}\text { Per cent. } \\
\text { Cured. }\end{array}$ \\
\hline $\begin{array}{l}\text { Tests } \\
\text { Experiment I : } \\
\text { Io mg. of neoarsphenamine per kg. of body } \\
\text { weight, followed immediately by a } 3-\mathrm{hr} \text {. } \\
\text { fever at I06. } 7^{\circ} \mathrm{F} .\left(4 \mathrm{I} \cdot 5^{\circ} \mathrm{C} \text {.) }\right.\end{array}$ & 23 & 23 & IOO \\
\hline $\begin{array}{l}\text { Experiment } 2 \text { : } \\
\text { Io mg. of neoarsphenamine per kg. of body } \\
\text { weight, followed immediately by a } 4 \text {-hr. } \\
\text { fever at } 106 \cdot 7^{\circ} \mathrm{F} .\left(4 \mathrm{I} \cdot 5^{\circ} \mathrm{C} \text {. }\right) \text {. }\end{array}$ & $2 \mathrm{I}$ & 20 & 95 \\
\hline $\begin{array}{l}\text { Experiment } 3 \text { : } \\
\text { 3-hr. fever at ro6 } \cdot 7^{\circ} \mathrm{F} .\left(4 \mathrm{I} \cdot 5^{\circ} \mathrm{C} \text {.), followed by }\right. \\
\text { the intravenous injection of Io } \mathrm{mg} \text {. of } \\
\text { neoarsphenamine per kg. of body weight. }\end{array}$ & 20 & I5 & 75 \\
\hline Controls & & & \\
\hline 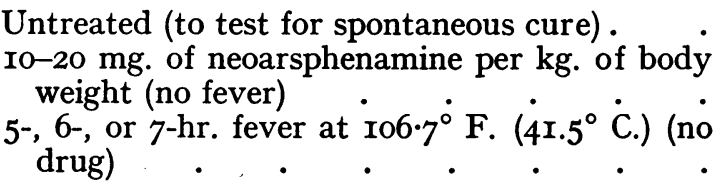 & I4 & 3 & Io \\
\hline
\end{tabular}

As soon as unequivocal syphilitic lesions developed (one to three months), I27 rabbits were treated in one of six ways (Table V). Twenty-three of the rabbits received a single subcurative injection of neoarsphenamine (Io mg. per kg. of body weight), followed by a single three-hour fever session at a rectal temperature of ro6.7 F. (4I.5 C.) ; all were cured. The criteria of cure were clinical examination for from one to three months, after which the animals were sacrificed and suspensions of testicular and popliteal lymphnode tissues were injected into normal 


\section{BRITISH JOURNAL OF VENEREAL DISEASES}

rabbits; no clinical or serologic evidence of syphilis appeared in these rabbits during a minimum period of six months. Further verification of cure was established by the successful transfer of the infection to the normal control rabbits at a later date.

Twenty-one syphilitic rabbits were given the same amount of neoarsphenamine, followed by a four-hour session of fever, for the purpose of determining the possible advantage of an additional hour of fever; all but one (or 95 per cent.) were cured. Thus, of 44 syphilitic rabbits treated with a single subcurative quantity of neoarsphenamine followed immediately by a subcurative session of fever therapy for three or four hours, 43 , or 98 per cent., were cured.

For the purpose of comparing the efficacy of the combined treatment when the drug was administered immediately after the fever session, rather than before, 20 syphilitic rabbits were given a three-hour session of fever at the same level, followed by an injection of the same quantity of neoarsphenamine; the results were distinctly inferior; only $\mathbf{1 5}$, or 75 per cent., were cured.

Fourteen syphilitic rabbits received no treatment as a control test for spontaneous cure; all remained infected; tissue transfers made from these animals resulted invariably in the infection of normal rabbits. Ten control rabbits received only a single injection of neoarsphenamine, ranging in dosage from to $\mathrm{mg}$. to $20 \mathrm{mg}$. per kg. of body weight ; only 3, or 33 per cent., were cured. As a control on the subcurative effect of either a three-hour or four-hour session of fever alone, 39 rabbits received five-hour, six-hour, or seven-hour sessions of fever (without neoarsphenamine) ; only 4, or ro per cent., were cured.

It is, then, quite apparent that a mode of therapy which combines a subcurative dose of neoarsphenamine with a subcurative session of artificial fever gives superior results in the treatment of experimental syphilis in rabbits when compared with the administration of greater amounts of the drug, or of fever alone. The time of administration of the antisyphilitic drug in relation to the fever is particularly significant. The results were distinctly better when the drug was administered immediately prior to, rather than immediately after, the fever session. It is probable that one of two factors, or 
both, operate in producing this favourable effect, namely, the more widespread distribution of the drug as the result of increased blood velocity and capillary dilatation, and the increase in the spirochætocidal effect of the chemical substance as a result of the elevation in body temperature. Eagle (30) has demonstrated that the antispirochætal action (in vitro) of both arsenic and bismuth compounds is increased approximately two-fold with a Io C. rise in temperature. Thus, it is probable that the minimal effective concentration of these chemical compounds is less when the body temperature is elevated to an effective level.

In collaboration with Dr. Robert A. Kehoe and his associates at the Kettering Laboratory of Applied Physiology, University of Cincinnati, we are engaged in an investigation of the in vivo minimum effective concentration of antisyphilitic chemical compounds in the blood, spinal fluid and tissues of animals and of human beings, with and without fever therapy.

\section{A. Personal Experiences in Experimental Treat- MENT OF EARLy Syphilis With ARTIFICIAL Fever COMBINED WITH CHEMOTHERAPY}

Our interest in the possibilities of utilizing artificial fever therapy as an adjunct to chemotherapy in the management of early syphilis was first aroused by the observations that the best results of combined feverchemotherapy occurred in patients with the earliest manifestations of neuro-syphilis, that the most prompt and satisfactory results occurred in such patients when even small doses of chemotherapeutic compounds were administered simultaneously with fever therapy, that mucocutaneous or osseous lesions which had previously resisted chemotherapy usually responded promptly when fever therapy was added to the usual therapeutic program, that chemo-resistant seropositive latent syphilis often yielded to the combined therapy, and that fever apparently exerted a protective function against sensitization reactions when arsenical compounds were injected at the height of fever. Thus it appeared that artificial fever therapy fortified and intensified the action of antisyphilitic chemical agents. The accumulated evidence of the thermolability of Spirochata pallida in experimental 


\section{BRITISH JOURNAL OF VENEREAL DISEASES}

syphilis in animals provided further encouragement to launch such studies in human beings, with full recognition of the fact that syphilis in rabbits and syphilis in human beings behave quite differently.

Consequently, since I932, we have subjected 77 patients with primary or secondary syphilis to the same course of combined artificial fever and chemotherapy as that employed in cases of neurosyphilis. During the first 6 years the usual course of fever therapy consisted of approximately 50 hours of fever at an average temperature of $105.8 \mathrm{~F}$. (4I C.), usually given in ten weekly sessions of five hours each. Since I937 such patients have received an average of $\mathrm{I} 2$ shorter sessions (three hours) of fever usually at more frequent intervals (twice or thrice each week), for an average total of 36 hours of sustained fever at the same average temperature level of r05.8 F. (4I C.). No essential differences were observed in the two groups, either as regards clinical or serologic responses.

At the outset of the experiment, it was decided to institute control studies to determine the efficacy of fever therapy alone, or of chemotherapy alone, of the same amount and kind as that used in patients treated by the combination of the two methods. After 6 patients with primary or secondary syphilis had been treated solely with a total of 50 hours of fever therapy, it was deemed unwise to continue with this part of the experiment, since 2 of these patients developed clinical relapse ; all were then given continuous chemotherapy. In the second control group of 15 patients with primary or secondary syphilis, in which 30 concurrent injections of the arsenic and bismuth compounds were given, 4 exhibited clinical relapse. It was quite apparent, therefore, that fever therapy alone or chemotherapy alone, as applied to these control groups, was inadequate.

Of the 77 patients treated for early syphilis with combined fever-chemotherapy, the records of I7 patients are incomplete for lack of adequate post-therapy observation. The 60 patients who have been re-examined clinically and serologically at frequent intervals were classified as follows : seronegative and dark-field positive primary syphilis, 8 patients; sero-positive primary syphilis, 24 patients; early secondary syphilis, 20 patients; and late secondary syphilis, 8 patients 
(Table VI). The period of observation following the combined course of treatment has varied from two years to nine years.

\section{Table VI.-Primary, Secondary and Latent SYPHILIS}

\begin{tabular}{|c|c|c|c|c|c|c|c|c|c|}
\hline \multirow[b]{2}{*}{ Type of Syphilis } & \multirow{2}{*}{$\begin{array}{l}\text { Number } \\
\text { Treated }\end{array}$} & \multirow{2}{*}{$\begin{array}{l}\text { Incom- } \\
\text { plete } \\
\text { Follow- } \\
\text { up Data }\end{array}$} & \multirow{2}{*}{$\begin{array}{c}\text { Included } \\
\text { for } \\
\text { Analysis }\end{array}$} & \multirow[b]{2}{*}{ "Cured" } & \multirow{2}{*}{$\begin{array}{c}\text { Im- } \\
\text { proved }\end{array}$} & \multirow{2}{*}{ 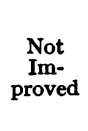 } & \multicolumn{3}{|c|}{ Blood } \\
\hline & & & & & & & \begin{tabular}{|l} 
Became \\
Negative
\end{tabular} & Less + & $\begin{array}{c}\text { Un- } \\
\text { changed }\end{array}$ \\
\hline Seronegative primary & 9 & $\mathbf{I}$ & 8 & 8 & & 一 & 一 & 一 & - \\
\hline Seropositive primary & 31 & 7 & $\dot{2} 4$ & 22 & $2^{*}$ & 一 & 24 & 一 & - \\
\hline Early secondary & 27 & 7 & 20 & 18 & $2 \dagger$ & 一 & 20 & - & - \\
\hline Late secondary & Io & 2 & 8 & 4 & $4 \ddagger$ & $\mathbf{I}$ & - & - & 一 \\
\hline Early latent & 19 & 2 & I 7 & - & - & - & I2 & 5 & 一 \\
\hline Late latent . & 32 & 5 & 27 & 一 & 一 & - & I3 & 10 & 4 \\
\hline
\end{tabular}

* Two patients required additional fever-chemotherapy.

$\dagger$ Two patients required additional fever-chemotherapy.

† Three patients required additional fever-chemotherapy.

(a) Seronegative, Dark-Field Positive, Primary Syphilis

None of the 8 patients with seronegative, dark-field positive, primary syphilis developed positive serologic reactions either during or following the course of combined therapy. None had received any previous chemotherapy. No living spirochætes could be demonstrated in the chancres after the first treatment. The average healing time of the chancres was two weeks.

\section{(b) Seropositive Primary Syphilis}

With 2 exceptions, the 24 patients with seropositive primary syphilis exhibited a rapid and progressive decline of the serologic reactions to negativity. The Kahn quantitative procedure was found to be of indispensable value in measuring the degree of serologic response and in determining the need for additional therapy in these patients. In the 2 exceptional cases additional feverchemotherapy was given because complete serologic negativity was not attained after the single course. The Kahn quantitative units remained stationary at 40 units in one case, and exhibited an increase from 40 to 360 units during the ten months following therapy in the other case. Both patients achieved serologic negativity following a second course of fever-chemotherapy. 


\section{BRITISH JOURNAL OF VENEREAL DISEASES}

(c) Secondary Manifestations during First Year of Disease

Of the 20 patients with early secondary manifestations of syphilis (occurring during the first year of the disease), I4 had received no previous chemotherapy, while 6 had had varying amounts before combined fever-chemotherapy was instituted. It was soon apparent that both the clinical and serologic responses were much more prompt and complete in those who had not received prior chemotherapy. It is also true that those who had had previous chemotherapy were referred to us for fever therapy because of their failure to respond to chemotherapy in the usual manner ; hence these patients probably represented an unusually resistant type.

All but 2 of the 20 patients achieved serologic negativity during or soon after the completion of the combined course. The 2 refractory patients required additional fever-chemotherapy before the serologic reactions were reversed to negative. One patient in this group had developed exfoliative dermatitis following injections of neoarsphenamine. Full adult doses of bismarsen were tolerated by this patient without incident when the injections were given in conjunction with the fever sessions. During the follow-up course of bismarsen injections he again developed exfoliative dermatitis. The Kahn quantitative units were 200 at this time. After a second course of 5 fever sessions combined with bismarsen, and followed by subsequent iddobismitol therapy (r9 injections), the serologic reactions became negative and have remained negative for the past five years.

\section{(d) Secondary Manifestations Occurring between the First and Second Years of Disease}

All of the 8 patients who exhibited late secondary manifestations of syphilis (occurring between the first and second years of the disease) had failed to respond to previous chemotherapy. Hence, the patients in this group represented serious treatment problems. During the usual course of chemotherapy these patients developed such secondary manifestations as macular or maculopapular eruptions, mucous patches, nasal vestibulitis, or recurrent ulcers at the site of the primary lesions; 2 patients also had concomitant periostitis. All had strongly positive blood serologic reactions. 


\section{FEVER THERAPY}

Four of these refractory patients responded both clinically and serologically to the combined therapeutic program. Three patients were improved following the usual course, but did not attain serologic negativity or complete clinical remission until they had received additional fever-chemotherapy. Included in this group is another patient who developed severe generalized exfoliative dermatitis following the administration of arsephenamine. Because of this patient's marked idiosyncrasy to arsenic, no chemotherapy was combined with the first four fever treatments. The exfoliative lesions disappeared after the third fever treatment. Before the fifth fever treatment was given the patient was tested with a I/I,000 gm. dose of neoarsphenamine. Two days later exfoliation again developed. At the beginning of the fifth fever treatment when the rectal temperature first reached I05 F. $(40.6 \mathrm{C}$.), a similar quantity $(\mathrm{I} / \mathrm{I}, 000 \mathrm{gm}$.$) of neoarsphenamine was injected$ intravenously. This injection was not followed by exfoliative dermatitis. During succeeding fever sessions, $0 \cdot \mathrm{Igm}$. injections of bismarsen were given when the rectal temperature reached I05 F. $(40 \cdot 6 \mathrm{C}$.) ; exfoliation did not occur. Because of this patient's extreme sensitiveness to arsenic when it was given without the protective action of fever, the usual follow-up course of chemotherapy was omitted. Despite the small total quantity of arsenic given in combination with artificial fever, this patient's serologic reactions, strongly positive before fever therapy was instituted, were reversed to negative and have remained so for five years.

In this connection, it is pertinent to record that one of our syphilitic patients has developed exfoliative dermatitis when the arsenical compound was employed concomitantly with artificial fever therapy.

Possible Intensification of Short-Term Chemical Treatment of Early Syphilis with ARTIficial FEVER

Encouraged by the foregoing observations and by the remarkable researches of Hyman, Chargin, Rice and Leifer (3I) on the five-day massive-dose chemotherapy of early syphilis by the intravenous drip method, we have engaged in an investigation to determine whether or not 


\section{BRITISH JOURNAL OF VENEREAL DISEASES}

it may be possible to abolish the disease in one day by combining a large dose of mapharsen with a single tenhour fever session. One objection to the "five-day intravenous drip method " is the significant proportion of arsenical sensitization reactions. It should be noted, however, that the toxic effects produced by mapharsen in the last series of cases reported upon by Hyman and his associates were remarkably less than those produced by neoarsphenamine in the series of patients treated previously by this method.

Since we have noted consistently that an individual's tolerance to arsenic is definitely increased during fever, the possibility suggested itself of eliminating or of diminishing the toxic chemical reactions by combining massive chemotherapy with artificial fever and at the same time to retain, and perhaps to fortify, its therapeutic effectiveness.

The present plan of treatment is as follows : A ten-hour session of fever at I06 F. (4I.I C.) has been adopted tentatively as the initial unit of fever, since these limits have proved to be safe and practical in the management of patients with refractory gonococcic infection. Prior to the fever session a single injection of 4 grains of insoluble bismuth is administered intramuscularly. During the first seven hours of the height of fever, $240 \mathrm{mg}$. of mapharsen are administered intravenously by the slow intravenous drip method. No additional antisyphilitic therapy is given.

While no conclusions are permissible since the period of post-therapy observation is as yet less than two years, the prompt resolution of clinical symptoms and the favorable serologic responses would indicate that further diligent inquiry is demanded. The results of this purely experimental undertaking will be made the subject of a later report.

\section{Value of Kahn Quantitative Procedure* as a TheraPeutic GUIDE}

Since I933, all blood and spinal fluid samples have been tested by the Kahn quantitative procedure, in addition

* The Kahn quantitative procedure with serum is a method for the differentiation of syphilitic serums on the basis of their potency. The regular 3-tube Kahn test is only partially quantitative, in that it is limited to a differentiation of 


\section{FEVER THERAPY}

to the Kahn standard diagnostic and presumptive tests. All specimens were also tested by the Kline or Kolmer methods or by both methods.

We have come to place great reliance in the additional information provided by the Kahn quantitative procedure. It furnishes a much more reliable and sensitive indicator of therapeutic response than the conventional qualitative diagnostic tests. In general, the fluctuations in the quantitative titer provide an indication of the reagin content of the serum. Such fluctuations usually reflect, and often anticipate, parallel trends in clinical response. We have often observed that a progressive rise in the quantitative titer gives warning of impending clinical relapse. In patients exhibiting such an upward trend in titer there is need for additional therapy or for a different type of therapy or for both. Sulkin and Gillick (32) have recently added further conviction to the many other favourable reports which have appeared in the use of the Kahn quantitative reaction. These authors recommend the general utilization of truly quantitative reactions because of its demonstrated value in determining the effectiveness of a particular method of therapy. The test is not technically difficult in the hands of experienced serologists and is easily adaptable to general use. Except for the presence of obvious clinical findings, we regard serial quantitative serologic testing of this type as the most important single therapeutic criterion.

\section{Discussion}

The facts speak for themselves. Artificial fevertherapy has come of age, in the thirteenth year since its birth. The magnificent work in malaria therapy, initiated by Wagner-Jauregg, adopted and expanded by capable workers in many lands, provided the stimulus which caused others to search for less hazardous ways of achieving a similar goal.

strongly and weakly potent serums from negative serums. The Kahn quantitative procedure provides an arbitrary measurement of the potency of serums giving positive reactions by the standard diagnostic test, expressed quantitatively on the basis of the number of reacting (Kahn) units. Thus, two serums giving four plus reactions with the standard Kahn test might differ radically in serologic potency, one serum showing perhaps 720 Kahn units and the other, 80 units. If, as is generally believed, the serologic reaction is an index of the state of the syphilitic infection and an index of the efficacy of treatment, a progressive decline in the number of reacting units provides evidence of favourable therapeutic response even though the standard diagnostic tests remain strongly positive. 


\section{BRITISH JOURNAL OF VENEREAL DISEASES}

Indulgence in controversy as to the relative merits of one or the other method of producing therapeutic fever should be ended. Each has its place in modern therapeutics. Malaria therapy is cheaper, unless one counts the cost of continued hospitalization and the loss of income to those who can be treated with artificial fever therapy without interruption of gainful employment. The cost of the apparatus for artificial fever therapy is not high if one considers that the cost per treatment is low. The new types of apparatus are designed to give continuous service for many years.

Malaria therapy has some advantages in the management of large numbers of patients congregated in understaffed, underequipped institutions for the mentally sick, but it is to be hoped that most neurosyphilitic patients in the future will be treated prophylactically or during the early manifestations of paresis. Thus the necessity for the admission of such patients to asylums for the insane will be eliminated. It is significant that artificial fever therapy has now replaced malaria therapy in many outstanding psychopathic hospitals. In isolated communities and in hopsitals not yet equipped for artificial fever therapy, malaria therapy should be employed.

The persistent claim that the malaria plasmodium exerts a specific beneficent influence in cases of neurosyphilis, apart from the production of fever, has little justification in the light of the developments of the past decade. Regardless of whether biologic, chemical or physical agencies are employed for the production of therapeutic fever, the results are entirely comparable. There is little room for further doubt as to the direct relationship between the height and duration of fever and the clinical results.

It is well known that malaria plasmodia provoke marked reticulo-endothelial stimulation, with an activation of phagocytic clasmatocytes, probably, in part at least, as a result of the destruction of red blood cells by the malaria plasmodia. It has been assumed by some workers that the clasmatocyte assists in some obscure way in the destruction of Spirochata pallida. The thoroughgoing hematologic studies by Doan, Hargraves and Kester (33) revealed that artificial fever causes a tremendous increase in the numbers of clasmatocytes, particularly in the lymphnodes, spleen and liver. 


\section{FEVER THERAPY}

Granulopoietic stimulation is much greater with artificial fever therapy than with malaria therapy. One of Doan's patients who was first treated with malaria developed temporary leucocytosis of 14,000 to $\mathrm{I}_{5}, 000$ per $\mathrm{cu}$. $\mathrm{mm}$. following each chill ; following subsequent artificial fever treatments in the hypertherm he developed transient leucocytosis as high as 40,000 to 60,000 per cu. $\mathrm{mm}$. To quote Doan : " Artificial hyperthermia by physical means not only provides the thermal factor of importance for the inactivation of the Treponema pallidum and the gonococcus, but has now been demonstrated to exert a profound effect upon the cellular equilibria of the body -in the directions which we believe, at the present time, to be the most effective in the mobilization of the defense forces of the body against these diseases." Here again, the uniformity of clinical results when adequate fever is produced by either malaria or artificial fever argues against any specific action by the malaria plasmodium.

To administer either therapeutic malaria or artificial fever therapy requires training and skill. The best results with either method are achieved by those who exercise the greatest diligence and care. It is a common observation that the death rate from malaria has declined from year to year as the workers in a clinic become more experienced in erecting safeguards against treatment complications.

Much more important than the type of apparatus selected for the administration of artificial fever therapy is the skill and devotion of the physicians and nursetechnicians who engage in this specialized work. Essentially similar results have been obtained by scores of workers employing a wide variety of physical modalities. The important considerations are: First, the adequate preliminary training of those who are to accept the responsibility for the selection and for the treatment of patients requiring fever therapy, and second, the selection of apparatus with which the treatments may be carried out with safety and with relative comfort to the patient.

\section{Summary aND Conclusions}

I. After a decade of rich and constantly enlarging experience with physically-induced artificial fever therapy, the successful results achieved by many workers 


\section{BRITISH JOURNAL OF VENEREAL DISEASES}

in many lands are sufficiently comparable to justify the categoric statement that artificial fever therapy is at least as effective as malaria therapy in the management of symptomatic or asymptomatic neurosyphilis. In the hands of many reliable investigators artificial fever therapy has yielded significantly superior results. Patients who have not responded well to malaria therapy have been benefited by subsequent artificial fever therapy.

2. There is unmistakable evidence that the extent of clinical improvement in neurosyphilitic patients is related directly to the height and the duration of fever. The thoroughly documented analyses made by statisticians of the U.S. Public Health Service provide proof that the clinical responses were distinctly inferior when relatively low temperature levels were employed. There is no longer any valid reason to assume that the malaria plasmodium exerts any specific effect upon Spirochata pallida.

3. Several investigators who have had long experience with malaria therapy and with artificial fever therapy have abandoned malaria therapy in favor of artificial fever therapy. This decision was determined largely by the observations that patients tolerate artificial fever therapy more readily, that a high proportion of neurosyphilitic patients can be treated with artificial fever on an ambulatory basis without interruption of gainful employment, and that treatment complications are minimized with artificial fever therapy.

4. Since continuous hospitalization is not a requirement for the artificial fever treatment of most neurosyphilitic patients, the cost of the treatment is not necessarily greater than with malaria therapy. If the patient remains at his regular employment during the course of artificial fever treatments, the cost is usually much less.

5. The employment of auxiliary chemotherapy in conjunction with any type of fever therapy is an essential requirement. There is evidence that the concurrent use of chemotherapy with artificial fever therapy increases the therapeutic effectiveness of both agencies.

6 . The hazards inherent in the various physical modalities used for the production of artificial fever during the first few years of the undertaking have been largely 


\section{FEVER THERAPY}

eliminated. Recognition of the physiologic changes produced by fever has led to the utilization of means to combat such effects. A procedure which was looked upon as a technical feat a decade ago may now be applied by skilled workers with a frequency which approaches routine.

7. Developments of the past few years have demontrated that equally favorable clinical and serologic results may be obtained with fewer total hours of artificial fever therapy, applied in shorter individual sessions at more frequent intervals. This practice permits the treatment of more patients at less cost.

8. The excellent results following the use of combined fever-chemotherapy in cases of asymptomatic neurosyphilis indicate that the patient's best interests are served by the prompt administration of this form of treatment.

9. The exudative forms of ocular syphilis, in contrast to the degenerative lesions, usually respond promptly and favorably to combined artificial fever-chemotherapy. Procrastination should be avoided in administering fever therapy in cases of exudative ocular syphilis in which chemotherapy is ineffective. There is reason to believe that primary optic atrophy may sometimes be improved or arrested by fever-chemotherapy.

Io. The addition of artificial fever therapy to the program of chemotherapy will produce serologic reversal in the majority of patients with resistant seropositive latent syphilis.

II. The general recognition of the inadequacies of present-day chemotherapeutic programs in the management of early syphilis has led to investigations of the possible usefulness of artificial fever therapy combined with chemotherapy in such cases. There is a growing body of evidence which indicates that artificial fever intensifies and fortifies the effectiveness of antisyphilitic chemical compounds. It seems possible that the time, effort and expense required for the eradication of early syphilis may be lessened as the result of future researches in this direction. At the present time such methods of treatment should be considered strictly experimental. The results achieved thus far, however, should stimulate other investigators to engage in. long-term, controlled experiments with a view to the introduction of more rapid, 


\section{BRITISH JOURNAL OF VENEREAL DISEASES}

more certain, less dangerous and less costly methods of treatment.

I2. In the hands of skilled and devoted workers artificial fever therapy provides the venereologist with a potent therapeutic weapon.

[Publication of an article by the same authors, entitled " Artificial Fever combined with Chemotherapy in Gonococcic Infections resistant to Chemotherapy " has unfortunately had to be postponed owing to lack of space. In it they report on a series of eighty-three patients suffering from complications of gonorrhœa, resistant or intolerant to chemotherapy, whom they have treated with artificial fever therapy, either alone or combined with chemotherapy. They found that a single ten-hour session of fever at a rectal temperature of $106 \cdot 6^{\circ} \mathrm{F}$. immediately following eighteen hours of adequate sulphanilamide or Promin treatment proved completely successful in thirty-one consecutive cases, and better than fever alone, chemotherapy only immediately before or during fever, or fever following ten days' intensive sulphanilamide therapy, but when there was none of the drug in the circulation.-ED.]

\section{BIBLIOGRAPHY}

I. Wagner-Jauregg, Julius : Derzeitige Behandlung der pro- ' gressiven Paralyse, Wiener klinische Wochenschrift, 52, I075, I939.

2. (a) O'Leary, Paul A., Bruetsch, Walter L., Ebaugh, Franklin G., Simpson, Walter M., Solomon, Harry C., Warren, Stafford L., and Vonderlehr, R. A. (Committee on Non-Specific Therapy, U.S. Public Health Service), assisted by Usilton, LidA J., and Sollins, I. V. : Malaria and Artificial Fever in the Treatment of Paresis, J.A.M.A., 115, 677-68I, August 3I, I940 ;

(b) Ibid., Ven. Dis. Inform., 21, 278-287, Sept., I940.

3. Barnacle, Clarke H., Ebaugh, Franklin G., and Éwalt, JACK R. : Treatment of Dementia Paralytica. Comparative Study of Combined Artificial Hyperpyrexia and Tryparsamide Versus Therapeutic Malaria: A Preliminary Report, J.A.M.A., 10\%, I03I-I034, Sept. 26, 1936.

4. Ewalt, Jack R., and Ebaugh, Franklin G.: Treatment of Dementia Paralytica (232 Cases) : A Five-Year Comparative Study of Artificial Fever Therapy and Therapeutic Malaria ; in press.

5. (a) Bennett, A. E., and Lewis, M. D. : The Prevention and Treatment of Neurosyphilis by Combined Artificial Fever and Chemotherapy, Amer. J. Syph., Gonor., and Ven. Dis., 22, 593-605, Sept., I938;

(b) Bennett, A. E. : Evaluation of Artificial Fever Therapy for Neuropsychiatric Disorders, Arch. Neurol. and Psychiatry, 40, II4III55, Dec., I938 ;

(c) Bennett, A. E., Nielsen, J. C., Fechner, A. H., and Cash, P. T.: Combined Artificial Fever and Chemotherapy in Dementia Paralytica, Arch. Phys. Ther., 20, 620-627, Oct., I929.

(d) Bennet, A. E., Nielson, J. C., and Fechner, A. H.: Advances 62 


\section{FEVER THERAPY}

in the Treatment of Dementia Paralytica by Combined Artificial Fever and Chemotherapy, Nebraska State Med. J., 25, I-4, Jan., I940 ;

(e) LEwis, M. D. : The Modern Management of Neurosyphilis, Dis. Nerv. System, 1, 332-336, Nov., I940.

6. BromberG, L. : Artificial Fever Therapy, J. Missouri State Med. Assoc., 36, 24-3I, Jan., I939.

7. (a) Trautman, J. A. : Summary of Results Obtained in Fever Therapy at the U.S. Marine Hospital, New Orleans, Louisiana, from June I, I934, to September I0, I938, Hospital News, U.S. Public Health Service, 6, I-43, Feb. I, I939;

(b) Ibid., Hyperpyrexia: Indications and Complications with Evaluation of Results Based on 5,500 Fever Sessions, New Orleans Med. and Surg. J., 92, 630, May, I940.

8. (a) Neymann, C. A. : The Treatment of Syphilis with Artificial Fever, Amer. J. Syph., Gonor., and Ven. Dis., 22, 92-I I7, Jan., I938 ;

(b) Ibid. Artificial Fever. Charles C. Thomas, Springfield, Illinois, and Baltimore, Maryland, I938.

9. (a) Hinsie, L. E., and Blalock, J. R. : Treatment of General Paralysis by Ultra High-Frequency Heating, N.Y. State Med. J., 36, I95I-I954, Dec. I5, I936 ;

(b) Blalock, J. R., and Hinsie, L. E. : Serology in General Paresis, Psychiatric Quarterly, 12, 84-II6, Jan., I938.

io. (a) Simpson, WAlter M., Kislig, Fred. K., and Sittler, E. C. : Ultrahigh Frequency Pyretotherapy of Neurosyphilis : A Preliminary Report, Ann. 1nt. Med., 7, 64-75, July, I933 ;

(b) Simpson, Walter M., Kislig, Fred. K., and Sittler, E. C. : Aus den Diagnostischen Laboratorien, der Venerischen Klinik und der Radiotherm-Abteilung des Miami-Valley-Hospitales und den Untersuchungslaboratorien der Frigidaire Corporation, Dayton, Ohio , translated by Professor Julius WAGNER-JAUREGG), Wiener medizinische Wochenschrift, 83, 7I7-72I, June 24, I933;

(c) Simpson, Walter M.: Influence of Radiotherm Pyretotherapy on Chloride Metabolism, J.A.M.A., 100, 67-68, Jan. 7, I933 ;

(d) Simpson, Walter M.: Artificial Fever., Amer. J. Clin. Path., 4, 373-375, July, I934;

(e) Simpson, WALTER M. : Artificial Fever Therapy: A Report of Researches at Miami Valley Hospital. Mayo Foundation Lecture. Proc. Staff Meet. Mayo Clinic, 9, 567-57I, I934;

( $f$ ) Simpson, Walter M. : Artificial Fever Therapy of Syphilis, Proc. Fifth Ann. Fever Conf., Dayton, Ohio, IIO-II4, May 2 and 3, I935 ;

(g) Kendell, H. Worley, Webb, Walter W., and Simpson, Walter M. : Artificial Fever Therapy of Gonorrhœal Arthritis: A Report of Thirty-One Cases, Amer. J. Surg., 29, 428-435 and 452, Sept., I935 ;

(h) Simpson, Walter M. : Artificial Fever Therapy of Syphilis, J.A.M.A., 105, 2132-2140, Dec. 28, 1935 ;

(i) Simpson, Walter M. : Studies on the Physiology of Fever, J.A.M.A., 106, 246, Jan. I8, I936 ;

(j) Culler, Arthur M., and Simpson, Walter M. : Artificial Fever Therapy in Cases of Ocular Syphilis, Arch. Ophth., 15, 624-644, April, r936 ;

(k) Simpson, Walter M.: Behandlung der Syphilis und der 63 


\section{BRITISH JOURNAL OF VENEREAL DISEASES}

Gonorrhœa mit künstlich erzeugtem Fieber, Wiener klinische Wochenschrift, 49, 779-783, June I9, I936; 49, 81 7-820, June 26, 1936 ;

(l) Simpson, Walter M.: Artificial Fever Therapy of Syphilis and Gonococcic Infections, Brit. J. Ven. Dis., 12, 133-166, July, I936 ;

(m) Simpson, Walter M.: Artificial Fever Therapy of Syphilis and Gonococcic Infections, New York State J. Med., 36, 1290-1306, Sept. 15, I936 ;

(n) Simpson, Walter M.: La Pyrétothérapie de la Syphilis et des Gonococcies, Bruxelles-Médical, 42, 1562-I564, Aug. I6, I936 ;

(o) Simpson, Walter M., and Kendell, H. Worley : Experimental Treatment of Early Syphilis with Artificial Fever Combined with Chemotherapy,

( $p$ ) Kendell, H. Worley, and Simpson, Walter M. : Artificial Fever Therapy of Sydenham's Chorea, Ohio State Med. J., 33, ro97I I00, Oct., I937 ;

(q) Simpson, Walter M., and Kendell, H. Worley : Artificial Fever Therapy, Colorado Med., 34, 782-795, Nov., I937 ;

( $r$ Kendell, H. Worley, Rose, Donald L., and Simpson, Walter M. : Fever Therapy Technic in Syphilis and Gonococcic Infections, Arch. Phys. Ther., 20, 6r4-6r9, Oct., r939;

(s) Simpson, Walter M. : Artificial Fever Therapy, Modern Medical Therapy in General Practice, The Williams and Wilkins Company, Baltimore, Maryland, Vol. I, pp. 492-528, 1940.

II. DE Kruif, Paul, and Simpson, Walter M. : Possible Significance of the Inhibitory Effect of Fever on Anaphylactic Pheromena, J. Lab. and Clin. Med., 26, I25-I30, Oct., I940.

I2. (a) Stokes, J. H., Cole, H. N., Moore, J. E., O'Leary, P. A., Wile, U. J., Clark, T., Parran, T., and Usilton, L. J. : Cooperative Clinical Studies in the Treatment of Syphilis, Ven. Dis. Inform., 13, I65-I82, May 20, I932 ;

(b) Ibid., 13, 253-292, July 20, I932;

(c) Ibid., 14, I-I2, Jan., I933.

I3. McGavic, J. S.: Fever Therapy for Ocular Diseases, Arch. Sphth., 19, 769-796, May, I938.

I4. Moore, J. E. : The Modern Treatment of Syphilis. Charles C. Thomas, Springfield, Illinois, and Baltimore, Maryland, p. 325, I933.

I5. Menagh, F. R. : The Treatment of Syphilis with Hyperpyrexia, with Observations on the Prognosis of Optic Atrophy, Amer. J. Syph., Gonor., and Ven Dis., 21, 609-621, Nov. I937.

I6. Usilton, LiDA J. : Trend of Syphilis and Gonorrhœea in the United States, Ven. Dis., Inform., 16, I47, 1935.

17. Chesney, Alan M.: Syphilis as a Problem in Immunity, South Med. J., 29, I230, I936.

18. PADGET, P.: Long-Term Results in the Treatment of Early Syphilis, Amer. J. Syph., Gonor., and Ven. Dis., 24, 692-731, Nov., 1940.

I9. Moore, Joseph E. : Prophylaxis and Treatment in the Control of Syphilis, South Med. J., 30, I49, I937.

20. WeIChBRodT, R., and JAhNEL, F. : Einfluss Höher Körpertemperaturen auf die Spirochäten und Krankheitserscheinungen der Syphilis im Tierexperiment, Deutsche med. Wchnschr., 45, 483-484, May I, I9rg.

“ 2I. (a) Bessemans, A., De Potter, F., and Hacouaert, R. : Sur 
deux formes d'aérothermothérapie locale des syphilomes testiculaires primaires du lapin, Compt. rend. Soc. de biol., 100, 757-76o, March I5, I929;

(b) Bessemans, A., Vercoullie, J., and Hacquaert, R. : Nouvel essai de thermoprophylaxie sociale antisyphilitique : traitement aérothermique local du chancre primaire, Rev. belge sc. méd., 1, 425-430, May, I929; Influence de diverses applications locales de la chaleur sur les accidents syphilitiques primaires et secondaires chez l'homme, Compt. rend. Soc. de biol., 101, 483-486, June I4, I929;

(c) Bessemans, A. : The Local Application of Heat as an Adjunct in the Social and Individual Prophylaxis of Syphilis, Urol. and Cutan. Rev., 34, 7I-9I, Feb., I930;

(d) Bessemans, A., and Thiry, U. : New Experiences with the Application of Local Heat Therapy (Hot-Water Baths and Diathermy by Long Waves Slightly Damped) in the Treatment of Primary and Secondary Syphilis in Man, Urol. and Cutan. Rev., 37, 377-39o, June, I933 ;

(e) Bessemans, A., and Thiry, U. : Nouveaux essais d'application de la thermotherapie locale de la syphilis primaire et secondaire chez l'homme, Bruxelles Méd., 13, 299-3II and 322-330, Jan. I5, I933;

( $f$ ) Bessemans, A. : Experimental Contribution to the Study of Antisyphilitic Hyperthermy Produced by Physical Agents, Brit. J. Ven. Dis., 14, 7I-84, April, I938 ; Amer. J. Syph., Gonor., and Ven. Dis., 22, 478-494, July, I938;

(g) Bessemans, A.: New Experimental Data on Artificial Hyperthermia, Ann. Int. Med., 11, I933-I945, May, I938 ;

(h) Bessemans, A. : Applications therapeutiques recentes de l'hyperthermie général provoquée par moyens physiques (physicopyrexie), Bruexelles Méd., 18, I6I3, Oct. 23, I938.

22. Schamberg, J. F., and Rule, Anna M.: Studies of the Therapeutic Effect of Fever in Experimental Rabbit Syphilis, Arch. Dermat. and Syph., 14, 243-255, Sept., I926 ; Therapeutic Effect of Hot Baths in Experimental Primary Syphilis in Rabbits, J.A.M.A., 88, I2I71218, April 16, I927; The Effect of Extremely Hot Baths in Experimental Syphilis, Arch. Dermat. and Syph., 17, 322-33I, March, I928.

23. (a) CARPENTER, C. M., and BoAK, RUth A. : The Effect of Heat produced by an Ultrahigh Frequency Oscillator on Experimental Syphilis in Rabbits, Am. J. Syph., 14, 346-365, July, I930 ;

(b) Carpenter, C. M., Boak, Ruth A., and Warren, S. L. : The Healing of Experimental Syphilis in Rabbits by Short Wave Fevers, J. Exper. Med., 56, 75I-762, Nov., I932 ;

(c) Boak, Ruth A., Carpenter, C. M., and Warren, S. L. : The Thermal Death Time of Treponema Pallidum in vitro, with Special Reference to Fever Temperatures, J. Exper. Med., 56, 74I-750, Nov., I932.

24. Levaditi, C., and DE Rothschild, H. : Etude expérimentale de la thermothérapie générale par les radiations à ondes courtes, $A n n$. Inst. Pasteur, 52, 23-67, Jan., I934.

25. Kolmer, J. A., and Rule, Anna M. : Hot Baths in Experimental Primary Syphilis of Rabbits and in Trypanosomiasis of Rats, Arch. Dermat. and Syph., 2\%, 660-662, April, I933 ; Bacterial Protein Fever in the Treatment of Syphilis in the Rabbit, Arch. Dermat. and Syph., 24, 546-553, Oct., I93I. 


\section{BRITISH JOURNAL OF VENEREAL DISEASES}

26. Boak, Ruth A., Carpenter, C. M., and Warren, S. L. : The Concurrent Treatment of Experimental Syphilis in Rabbits with Fever and Neoarsphenamine. Presented before the American Public Health Association, October, I940 ; in press.

27. Kyrle, J.: Die Malariabehandlung der Syphilis, Wien. klin. Wchnschr., 37, I106-1109, Oct. 23, I924.

28. (a) Richet, C., Jr., and Dublineau, J. : Pyréto et chimiothérapie associées dans le traitment de la syphilis du lapin, $J$. de physiol. et de path. gén., 31, 794-8II, Sept., I933 ;

(b) Richet, C., Jr., Dublineau, J., and Joly, F. : Pyréto et chimiothérapie associées dans la syphilis primaire et secondaire: étude expérimentale et clinique, Presse méd., 41, I649-165I, Oct. 25, I933 ;

(c) Richet, C., Jr., and Dublineau, J. : La pyrétothérapie de la syphilis, Paris méd., 1, I97-205, March 3, I934.

29. Neymann, C. A., Lawless, T. K., and Osborne, S. L.: The Treatment of Early Syphilis with Electropyrexia, J.A.M.A., 10\%, I94, I936.

30. (a) EAGLe, H., and Mendelsohn, W.: On the Spirocheticidal Action of the Arsphenamines on Spirocheta pallida in vitro, Science, 87, I94, I938 ;

(b) EAgLe, H.: The Minimal Effective Concentrations of Arsenic and Bismuth Compounds on $T$. pallidum in vitro in Relation to the Therapeutic Dose, Amer. J. Syph., Gonor., and Ven. Dis., 23, 310, I939.

3I. (a) Chargin, L., Leifer, W., and Hyman, H. T. : The Application of the Intravenous Drip Method to Chemotherapy as Illustrated by Massive Doses of Arsphenamine in the Treatment of Early Syphilis, J.A.M.A., 104, 878, March I6, I935 ;

(b) Hyman, H. T., Chargin, L., and Leifer, W. : Massive Dose Arsenotherapy of Syphilis by the Intravenous Drop Method: Five-Year Observations, Amer. J. Med. Sc., 197, 480-485, April, I939;

(c) Hyman, H. T., Chargin, L., Rice, J. L., and Leifer, W.: Massive Dose Chemotherapy of Early Syphilis by the Intravenous Drip Method, J.A.M.A., 113, I208-1214, Sept. 23, I939;

(d) Hyman, H. T., Chargin, L., and Leifer, W. : Massive Dose Arsenotherapy by the Intravenous Drip Method, Amer. J. Syph., Gon., and Ven. Dis., 23, 685-69I, Nov., I939;

(e) Hyman, H. T. : Massive Dose Chemotherapy by the Intravenous Drip Method, Bull. N.Y. Acad. Med., 17, I35-I53, Feb., I94I.

32. Sulkin, S. E., and Gillick, F. G.: The Quantitative Kahn Reaction as a Guide to Antisyphilitic Therapy, Amer. J. Syph., Gonor., and Ven. Dis., 28, 77-84, Jan., I94I.

33. (a) Doan, C. A., Hargraves, M. M., and Kester, L. : Differential Reaction of Bone Marrow, Connective Tissue, and Lymph Nodes to Hyperpyrexia, Abstracts and Discussions, First Internat. Conf. on Fever Therapy, Paul B. Hoeber, Inc., N.Y., pp. 40-4I, I937 ;

(b) DoAn, C. A. : Peripheral Blood Phenomena and Differential Response of Bone Marrow and Lymph Nodes to Hyperpyrexia, Radiology, 30, 382-389, March, I938. 